\title{
MEASUREMENT OF INDUCTANCE BY ANDERSON'S METHOD, USING ALTERNATING CURRENTS AND A VIBRATION GAL- VANOMETER.
}

By Edward B. Rosa and Frederick W. Grover.

\section{HISTORY OF THE METHOD.}

Several modifications of Maxwell's method ${ }^{a}$ of comparing an inductance with a capacity have been proposed in order to obviate the double adjustment of resistances necessary in that method. Maxwell showed

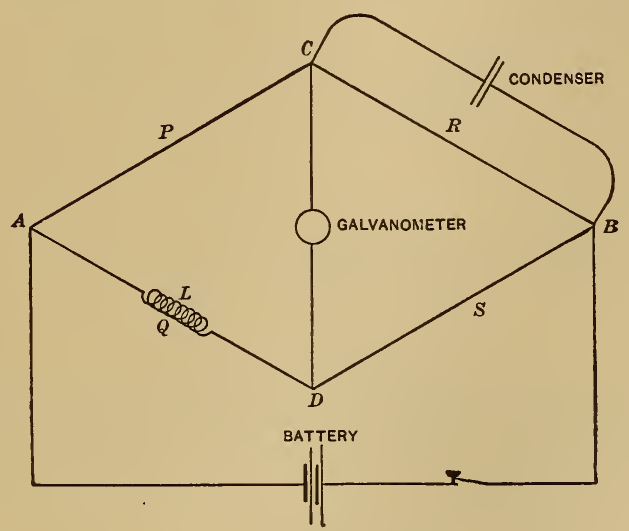

FIG. 1.-Maxwell's method.

that if (1) the bridge is balanced for steady currents and at the same time (2) the resistances are so chosen that there is no deflection of the galvanometer when the battery current is suddenly closed or broken, then

$$
L=C R Q=C P S
$$

where $L$ is the inductance in the $\operatorname{arm} A D$, the resistance of which is 
$Q, C$ is the value of the capacity in parallel with $R$, and $P, R$, and $S$ are noninductive resistances.

In order to satisfy both of these conditions two of the arms of the bridge must be varied simultaneously, so that the balance for steady currents may be maintained while the balance for transient currents is sought. This is generally a tedious process, although by means of a small variable inductance in $Q$, in addition to the inductance to be measured, and a multiple valued condenser the process might be considerably accelerated.

In 1891 Professor Anderson proposed ${ }^{a}$ an important modification of Maxwell's method, which consisted in joining the condenser to a point $E$, separated from $C$ by a variable resistance $r$. The bridge being balanced for steady currents by varying any one of the four arms of the bridge, the balance for transient currents is then made by

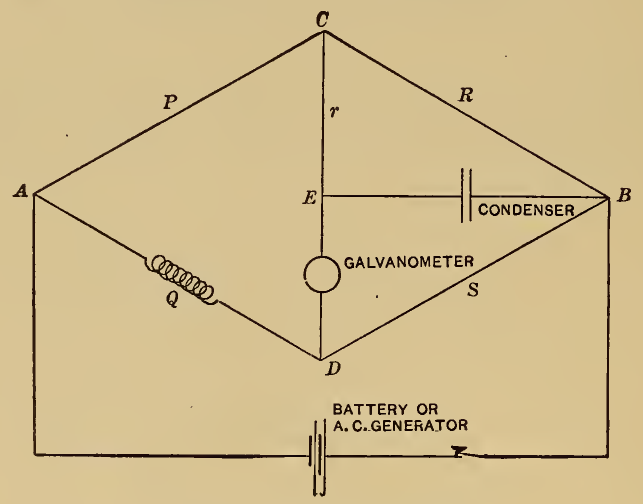

FIG. 2.-Anderson's method.

varying $r$, which does not disturb the balance of the bridge for steady currents. This change, which rendered the two adjustments independent, removed at once a most serious difficulty and made the method thoroughly practicable.

Anderson's demonstration for the case of transient currents gives for the value of the inductance (changing the letters to correspond to fig. 2)

$$
L=C[r(Q+S)+P S]
$$

If $r=0, L=C P S$, as in Maxwell's method.

In the use of Anderson's method $r$ may be small, so that $C P S$ is the principal part of the expression for the inductance, or it may be larger, and the first term, $C r(Q+S)$, represents the larger part of $L$. Thus a considerable range of values of inductance may be measured 
without changing the arms of the bridge or the capacity of the condenser.

Stroud and Oates ${ }^{a}$ have proposed another modification of Maxwell's method, which they have used with much success in measuring inductances. Instead of employing an interrupted current from a battery, as Anderson had done, they used an alternating current and an alternating-current galvanometer, the latter being essentially a d'Arsonval galvanometer, with the field magnet laminated and strongly excited by an alternating current from the generator. The galvanometer was thus made very sensitive, and to increase the sensitiveness still further the resistance $r$ was placed outside the bridge, as shown in Fig. 3. It will be seen that this arrangement differs from Maxwell's only in separating the point $B$ from the terminal of the condenser by the

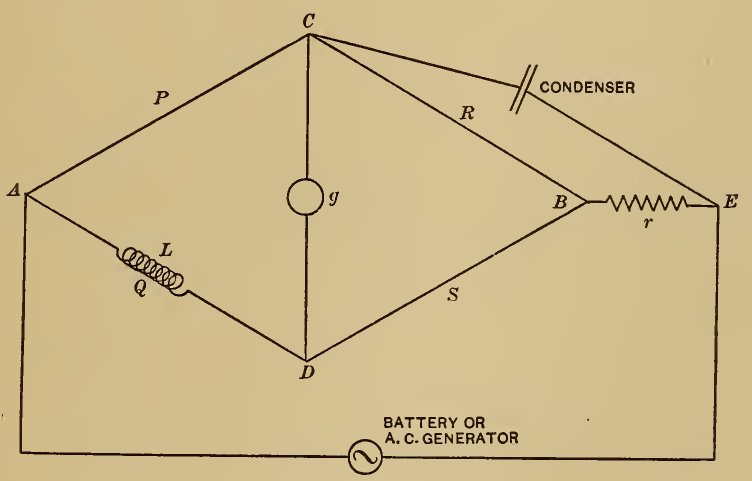

Fig. 3.-Stroud's method.

auxiliary adjustable resistance $r$, which in Anderson's method is in the galvanometer circuit between $C$ and $D$. As the resistance $r$ is sometimes several hundred ohms, it reduces the sensibility when in the galvanometer circuit, whereas in the arrangement of Fig. 3 the electromotive force can be increased if $r$ is large, and so keep the same current in the bridge as when $r$ is small, and thus maintain the sensibility.

The expression for the inductance $L$ in Stroud's method (changing the letters to correspond with Fig. 3) is

$$
L=C[r(Q+P)+P S],
$$

which closely resembles the formula for Anderson's method, but differs in having $Q+P$ in the first term instead of $Q+S$. 
Professsor Fleming has pointed out that Stroud's arrangement may be regarded as conjugate to Anderson's, the galvanometer and source of current being interchanged, Fig. 4. In this case the formula is exactly the same as for Anderson's method. If, however, Fig. 4 be rearranged so as to agree with Fig. 3 , it will be found that the arms $P$ and $S$ are interchanged, and consequently that these letters must be interchanged in the formula for $L$. This changes equation (2) into equation (3).

Fleming and Clinton have employed Anderson's method for the measurement of small inductances, using a battery and a rotating commutator and galvanometer, ${ }^{a}$ and later Fleming employed an interrupted current, produced by a vibrating armature, and a telephone. ${ }^{b}$

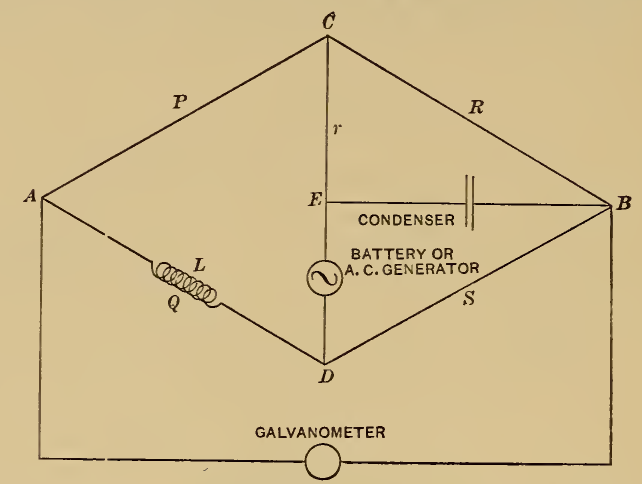

FIG. 4.-Showing Stroud's method as conjugate to Anderson's.

During the past two years we have employed Anderson's method for the measurement of both large and small inductances, using (1) a battery as a source of current and a d'Arsonval galvanometer, with a rotating commutator to interrupt and reverse simultaneously the current and galvanometer terminals; or (2), what has proved more satisfactory, an alternating current and a vibration galvanometer, the latter being tuned to the frequency of the current furnished by the generator.

\section{ADVANTAGES OF THE METHOD.}

We have found the method rapid and convenient in practice and the vibration galvanometer sufficiently sensitive to permit very accurate settings. As compared with other methods of accurately measuring inductance, it possesses striking advantages, some of which will here be specifically mentioned. 
(a) All methods of measuring inductances without the use of a condenser (or other known inductance) require an accurate knowledge of the frequency of the alternating current employed. It is not difficult to determine accurately the mean frequency of an alternating current, even when the generator is inaccessible, as a counter may be employed to record on a chronograph the number of revolutions in a given time; moreover, the speed of the generator may be maintained sufficiently constant to enable good settings to be made. But to hold the speed steady enough to make settings of a high order of accuracy is difficult and requires an assistant to control the speed. With Anderson's method, even with a tuned galvanometer, slight changes of frequency are not detrimental, and hence the labor of taking the observations is greatly reduced.

(b) The inductance is determined in terms of a capacity, in addition to several resistances, which are also required in other methods of measuring inductance. A capacity can be measured by Maxwell's bridge method, using a commutator, with very great exactness, provided care is taken in choosing the resistances of the arms of the bridge, ${ }^{a}$ and also provided the temperature of the condenser is taken and a temperature correction subsequently applied whenever necessary. The capacity of a condenser is not the same for slow charges as for rapid charges, and hence, if Anderson's method is used for transient currents, the capacity employed in the formula should correspond to the conditions of the experiment. As the successive makes and breaks of the current are likely to be irregular, the result would be that the effective capacity would rary slightly in successive trials, eren with the best mica condensers. On the other hand, using an interrupted or alternating current of constant frequency, the capacity is uniform and definite, and if it is measured at the same frequency there is no uncertainty as to its value. In our experiments we employ an eight-pole generator, giving four complete cycles in each revolution. To this generator is joined the commutator which is employed in charging and discharging the condenser when measuring its capacity, the commutator having four segments, and hence charging and discharging the condenser four times in each revolution. Thus the frequency of charge and discharge of the condenser may be made exactly the same in use as when its capacity is measured. The change of capacity of a condenser with the frequency is very slight, but in measurements of the highest accuracy it is well to eliminate the slight uncertainty due to change of frequency. 
(c) The formula for calculating the inductance is simple, and comparatively few quantities have to be measured. There is, however, a sufficient number of variables to permit measuring inductances of a very wide range of values with the same bridge, using comparatively few values of the capacity.

(d) The method is particularly well adapted to measure inductance by the substitution method, where the inductance to be determined is replaced by a standard of nearly equal value. The difference between them can then be measured with very great precision, the residual errors of the bridge being nearly if not entirely eliminated.

There are no disadvantages of the method that are not shared by other methods, except so far as the use of a condenser may be deemed a disadvantage. There are, however, some sources of error to be guarded against which we shall discuss later.

\section{ADVANTAGES AND DISADVANTAGES OF A VIBRATION GALVANOMETER.}

When the bridge is completely balanced (the conditions for a resistance balance and an inductance balance being simultaneously satisfied) the current will be zero in the galvanometer at every instant. If, however, the steady current balance is slightly disturbed by the heating of the resistances, especially that of the inductance coil to be measured, no adjustment of the variable resistance $r$ will make the current in the galvanometer zero. The result is that the needle of the galvanometer will have a certain minimum amplitude of vibration when $r$ is correctly set. If now one of the resistances (say Q) is slightly altered, a complete balance may be attained and the needle will be perfectly still. This will be seen to be a distinct advantage, for one is always certain, when the needle is quiet, that both of the conditions of the bridge are satisfied; namely, the condition of the simple Wheatstone bridge $(P S=R Q)$, and the condition imposed by the presence of the inductance which requires a particular value for the resistance $r$. But the vibration galvanometer does more than merely save the trouble of going back to the use of a direct current and a direct current galvanometer to see whether the balance still holds; for, when an appreciable current is used, the resistance may be changing sufficiently to render such a test insufficient. The vibration galvanometer, on the other hand, insures that at the very moment when the inductive balance is attained the resistance balance also holds, and thus no error from this cause can enter.

Still further, if the resistance of the inductive coil, or of the arms of the bridge, is different when carrying alternating current from its resistance when carrying direct current (as it always is, although the difference is very small for tine wires and low frequencies), the vibra- 
tion galvanometer takes account of the true resistance under the conditions of the experiment as a direct current galvanometer could not do. This is of considerable importance in measuring the inductance of coils of large wire. Neither a telephone nor an alternating current d'Arsonval galvanometer possesses this advantage.

In practice it is not necessary to make a close adjustment of the direct-current balance at all, as this can be determined just as well by the vibration galvanometer. In our work a graduated scale is viewed in a telescope by reflection from the mirror of the vibration galvanometer, the filament of an incandescent lamp used to illuminate the scale being also seen in the telescope. When an approximate adjustment of $r$ and $Q$ is secured, the filament will appear somewhat broad-

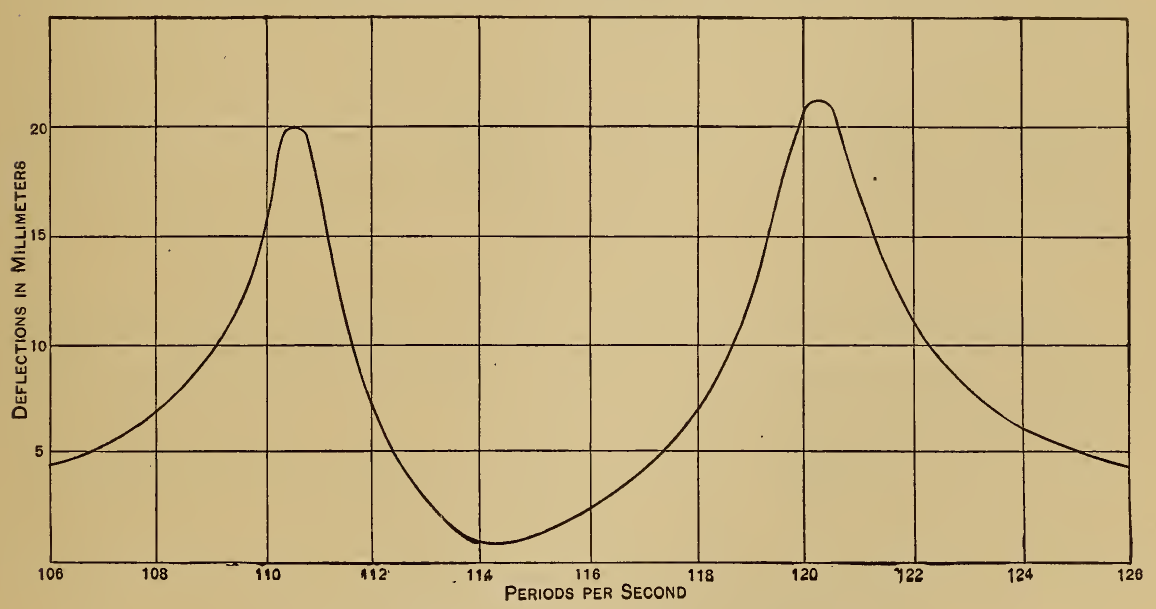

FIG. 5.-Sensibility curve of the vibration galvanometer.

ened by the slight vibration of the needle of the galvanometer. Small changes in $r$ and $Q$ are then made successively until the filament appears as a fine line and the lines on the scale are perfectly distinct ${ }^{a}$. This adjustment can be made so delicately that a change in $r$ or $Q$ of one part in a hundred thousand can be detected, when measuring inductances of large values.

The chief disadvantage of the vibration galvanometer lies in the fact that its sensibility decreases rapidly when the frequency of the current varies from the natural period of the galvanometer. The sensibility is nearly constant for a range of about one-half per cent in the frequency but falls off rapidly when the frequency goes beyond this range. 
In order to maintain the frequency at the point of maximum sensibility a Maxwell bridge is employed, as when measuring the capacity of a condenser. The condenser capacity and resistances of the bridge remaining constant, any change in speed causes a deflection of the galvanometer. An adjustable carbon resistance in the armature circuit of the driving motor permits the speed to be adjusted so that the deflection is reduced to zero. The motor is driven by current from a storage battery, and hence the changes in speed are relatively small. A glance at the galvanometer scale at any time shows whether the speed is correct, and if not, it is quickly adjusted by means of the rheostat.

Fig. 5 gives the sensibility curve of the vibration galvanometer, showing two peaks of high sensibility at 110.6 and 120 vibrations per second, respectively. At a frequency of 115 the sensibility is very low-much less than it is at frequencies outside the peaks of maximum sensibility. The curve is affected by changes of temperature, and can be altered at pleasure by varying the length and tension of the suspension wire.

\section{THE APPARATUS.}

A Rubens vibration galvanometer, ${ }^{a}$ having a resistance of $200 \mathrm{ohms,}$ is used. Its frequency may be varied between 100 and 200 per second, but has been used chiefly at about 110 .

The several resistances are of manganin, and are all submerged in oil, to prevent heating and to enable their temperatures to be more accurately determined. The values of these resistances have been carefully measured every day that measurements of inductance have been made, when results of the highest accuracy have been sought. In series with the resistances $r$ and $Q$, and forming part of them, are two slide wires which enable these resistances to be adjusted to 0.001 ohm, or even less, when necessary.

In order to eliminate as rar as possible the errors due to slight changes in the arms $P$ and $R$ of the bridge, as well as any difference in their residual inductance and capacity, these resistances are always made equal and a commutator is employed to reverse them; a pair of readings is taken in every case, the mean of which is used in the calculation. The resistances $Q$, and $S$ were taken from two resistance boxes, in which the higher coils are subdivided to reduce the electrostatic capacity of the coil. We found in some of our early work that the residual capacity or inductance of noninductive resistances may be considerable; in the lower resistance coils the inductance predominates, and in the higher coils the capacity predominates. The connecting 


\begin{tabular}{|c|c|c|c|c|}
\hline 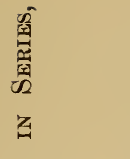 & む & $\overbrace{\substack{11 \\
1}}^{n}$ & 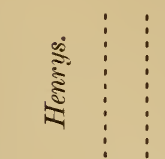 & $\vdots \begin{array}{c} \\
\vdots \\
\vdots \\
\vdots\end{array}$ \\
\hline 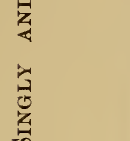 & 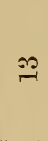 & 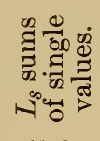 & 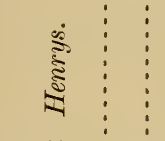 & $\frac{1}{9}$ \\
\hline $\begin{array}{l}\text { 晨 } \\
\text { 量 }\end{array}$ & $\stackrel{ }{=}$ & 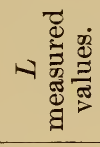 & 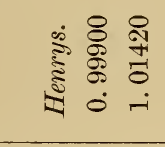 & 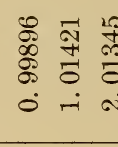 \\
\hline$\sqrt{3}$ & $\sigma$ & $\circlearrowright$ & 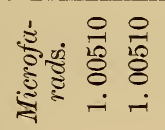 & $\begin{array}{lll}\overline{1} & & = \\
8 & 18 \\
8 & 8 & 8 \\
-1 & -1\end{array}$ \\
\hline प्र & $\infty$ & 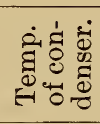 & $\circ \begin{array}{l}\vdots \\
\circ \\
\vdots\end{array}$ & $\begin{array}{l}\sim \\
\stackrel{\sim}{g} \\
\stackrel{\sim}{-}\end{array}$ \\
\hline 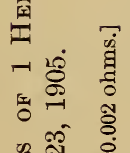 & N & $\begin{array}{l}a \\
+ \\
\vdots \\
\text { a }\end{array}$ & 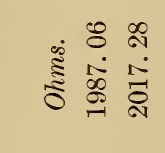 & 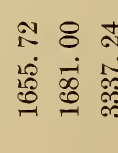 \\
\hline 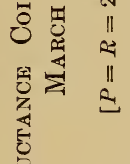 & 0 & 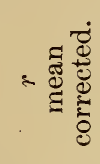 & 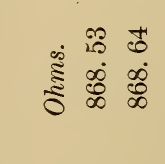 & 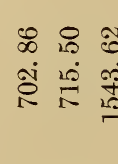 \\
\hline I & 20 & 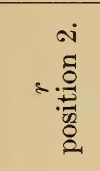 & 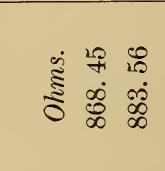 & 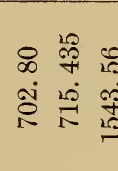 \\
\hline 至 & + & 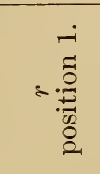 & 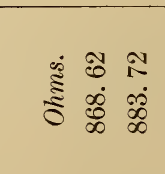 & 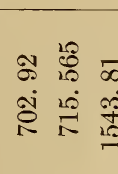 \\
\hline 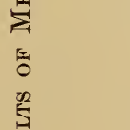 & $\infty$ & $c 2$ & 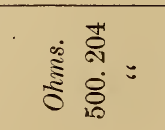 & 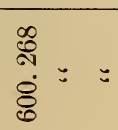 \\
\hline 蛋 & $\propto$ & $\frac{\dot{\theta}}{\ddot{\delta}}$ & I 0 & $\begin{array}{lll}0 & 0 \\
& 0\end{array}$ \\
\hline 6 & - & $\dot{0}$ & 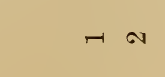 & $\infty+20$ \\
\hline
\end{tabular}




\begin{tabular}{|c|c|c|c|c|c|}
\hline+ & $\stackrel{\infty}{11}$ & 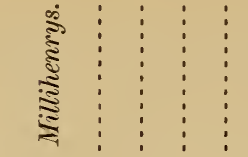 & \begin{tabular}{ll|l}
20 & 0 \\
0 & 0 & 0 \\
0 & 0 & 0 \\
+ & + & + \\
+ & + & +
\end{tabular} & \begin{tabular}{ll|l}
$\overrightarrow{0}$ & $z$ & $\overrightarrow{0}$ \\
0 & 0 \\
0 & $\dot{0}$ & 0 \\
+ & + & +
\end{tabular} & \\
\hline$\Re$ & 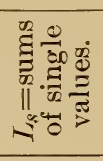 & 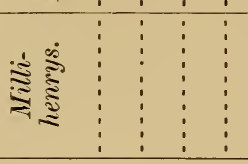 & 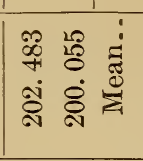 & 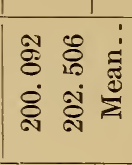 & \\
\hline I & 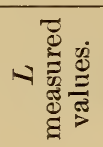 & 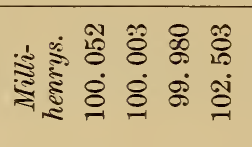 & 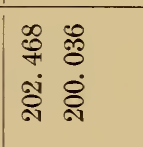 & 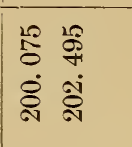 & 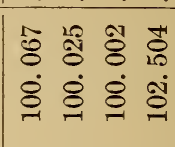 \\
\hline$\sigma$ & 0 & 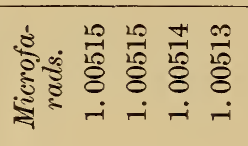 & 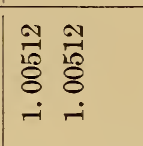 & $\begin{array}{ll}= & =1 \\
80 & 8 \\
8 & 8 \\
-i & -1\end{array}$ & 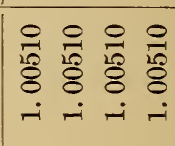 \\
\hline$\infty$ & 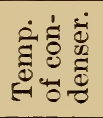 & 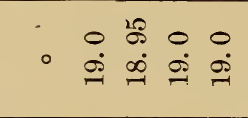 & 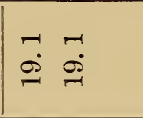 & & 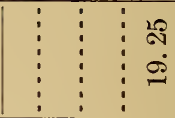 \\
\hline N & 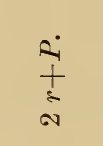 & 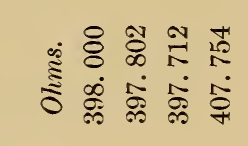 & 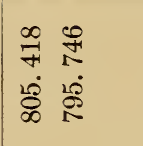 & 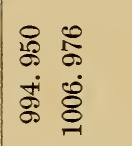 & 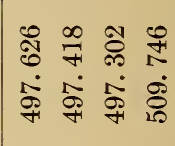 \\
\hline 0 & $=$ 跣离 & 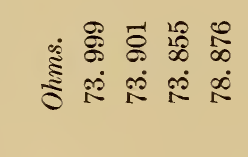 & 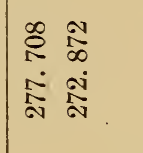 & 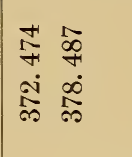 & 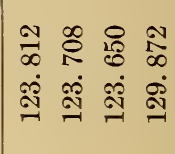 \\
\hline 10 & 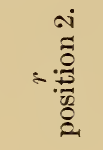 & 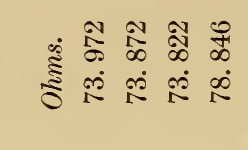 & 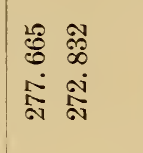 & 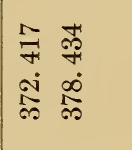 & 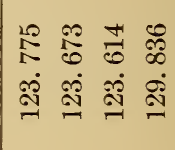 \\
\hline$r$ & 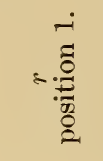 & 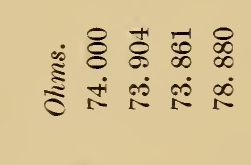 & 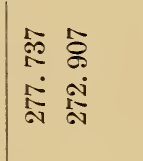 & 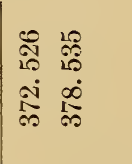 & 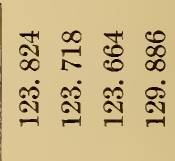 \\
\hline$\infty$ & is & 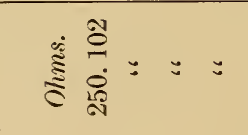 & 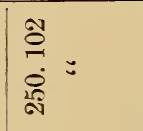 & $\begin{array}{l}\infty \\
\ddot{8} \\
\dot{8} \\
\dot{\alpha}\end{array}$ & $\begin{array}{l}\infty \\
\ddot{\delta} \\
\dot{8} \\
\dot{\sim}\end{array}==$ \\
\hline$\sim$ & ) & $\varangle \leadsto=0$ & $\mid \begin{array}{ll}0 & 0 \\
+ & + \\
\pm & 4\end{array}$ & $\begin{array}{l}\infty 0 \\
\pm \pm \\
4=\end{array}$ & $\triangleleft \leadsto \Xi 0$ \\
\hline$\tau$ & $\dot{\mathrm{z}}$ & tor $\propto$ & 100 & $\sim \infty$ & $0=$ \\
\hline
\end{tabular}


leads have substantial terminals and the resistances of these leads, in thousandths of an ohm, is stamped on the terminals. Their values are always included in making up the corrected resistances of the bridge.

The measurements shown in Tables I and II, made March 23, illustrate the results obtained in the determination of inductances of one benry and one-tenth henry. An electromotive force of about 50 volts was employed on the bridge.

Fig. 6 shows how the commutator was connected to the bridge so as to reverse $P$ and $R$, which are equal. Formula (2) in this case $(Q=S)$ reduces to

$$
L=C S(2 r+P) \text {. }
$$

Columns 4 and 5 give the nominal values of $r$ in the two positions of the commutator, and column 5 the mean value, corrected from the

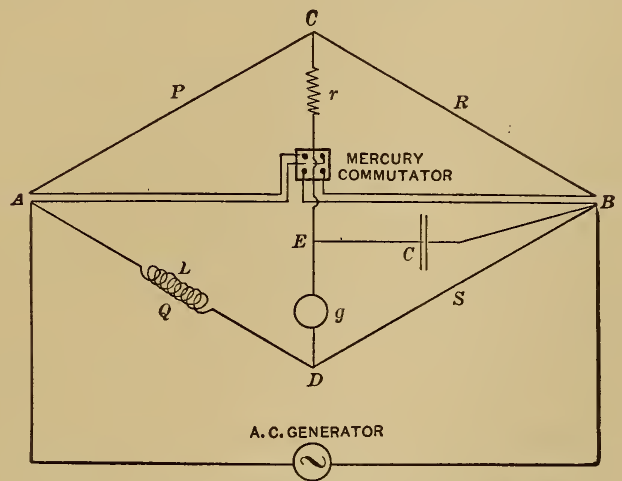

FIG. 6.-Showing commutator for interchanging two arms of the Anderson Bridge.

results of the latest comparison of the resistances with standard resistances.

Column 9 gives the capacity of the condenser $C$. Where two inductances are measured in series the measured sum is given in column 10, and the sum of the separate values are given in the next column. The last column gives the differences between these measured values and the sums of the separate values. While these differences are very small, averaging less than one in ten thousand, they are appreciable and always positive. This indicates that there may be some constant source of error in the bridge.

\section{SOURCES OF ERROR.}

The results given above show that measurements of inductance of very great precision can be made by Anderson's method, provided there are no constant errors of appreciable magnitude entering into 
the results. Such errors might be due to any one of the following causes:

(a) The residual inductance or capacity of the resistance $r$ and of the arms of the bridge (not including, of course, the inductance of the coil in $Q$ which is being measured) may introduce a constant error in $L$. As stated above, we have always made the arms $P$ and $R$ equal in value and reversed them by a commutator, in order to eliminate any difference there may be in their resistances or in their inductances or capacities. But the differences between $Q$ and $S$ can not thus be eliminated. The total resistance of $Q$ is, of course, equal to $S$, since $P=R$ (except for a small change due to residual inductances, to be discussed later), but part of this is in the inductive coil itself. Residual inductance in the noninductive part of $Q$ makes the measured value of $L$ too large, and, conversely, capacity would make it too small. The effect of inductance or capacity in $S$ is of opposite sign to that of $Q$, and hence if the resistances of $Q$ and $S$ are similar, that is, made up as far as possible of the same kind of coils, then their effects will balance except for that part of $S$ which equals the resistance of the inductive coil. In our work $S$ was fixed in any given case, and $Q$ was varied to secure a balance; thus $Q$ usually contains a number of small resistances in addition to the slide wire, and these can not be counterbalanced exactly by $S$.

(b) The inductive coils must be removed some distance from the bridge and from each other when two or more are measured at once. This requires leads of one to three meters in length (for the larger inductances), and these leads may affect the measured value of the inductance. If they are close together, so as to be noninductive (as twisted lamp cord, for instance), they possess an appreciable capacity; and if far enough apart to be free from eapacity, they possess measurable inductance. In measuring small inductance coils the capacity effect is small, and it is better to have the leads close together and as short as is safe. With large inductances the capacity of the leads is more important, and it is better to have them farther apart, to reduce it to a minimum. The inductance of the leads can then be calculated (or separately measured) and applied as a correction, if desired, or the same leads may always be employed with a given coil and considered as a part of the coil. The inductance of the wires joining the condenser to the bridge tends to reduce the capacity in the ratio of $p l$ to $\frac{1}{p c}$ or $p^{2} l c$ to unity, where $l$ is the small inductance of the leads; on the other hand, if these leads are close together, their capacity is added to that of the condenser. In our experiments, where the leads 
were short and wide apart, both these effects were inappreciable. But if currents of high frequency are used, particularly with large capacity, the error due to the inductance of the leads may be appreciable; on the other hand, with small condenser capacity, the error due to the capacity of lead wires near together (as a twisted lamp cord) may be considerable and of opposite sign to the other. In precision measurements, therefore, care should be taken that no error is introduced in this manner.

(c) The inductive coil itself has a certain electrostatic capacity which modifies its measured inductance by an amount depending on the frequency of the current and the inductance of the coil, as well as its capacity. $"$ The approximate value of the expression for the measured inductance $L^{\prime}$ in terms of the true inductance $L$ is

$$
L^{\prime}=L\left(1+p^{2} c L\right)
$$

where $c$ is the electrostatic capacity of the coil and $p=2 \pi$ times the frequency. In practice, $c$ is found by measuring $L^{\prime}$ at two different frequencies; it is too small to be important for the smaller values of inductance at low frequencies. One of our inductance coils, having an inductance of 1 henry, has a capacity of $1 \times 10^{-10}$ farads. For a frequency of 112 , this value makes the correction term $p^{2} C L$ in the above expression .00005 , a quantity which can be detected, but which is not a large error. If, however, the frequency were ten times as great, this term would become .005 , a very important correction.

The electrostatic capacity of a coil can be made relatively small by winding it in a deep channel, so that there are many layers and comparatively few turns in a layer. This, however, reduces its inductance, and in practice it is better not to depart very far from the form giving maximum inductance. The electrostatic capacity of the cord, as already pointed out, increases the value of this correction term.

(d) The capacity of the condenser, as already stated, can be determined with very great accuracy, and by taking careful account of the temperature of the condenser and its temperature coefficient, there will be very little uncertainty in the value of the capacity. The question remains, however, as to what effect the absorption in the condenser produces on the measured value of the inductance when used in Anderson's method. The effect of absorption is to cause the current to lag a little behind its phase in a perfect condenser. That is, it is in advance of the electromotive force by a little less than $90^{\circ}$. We give below a theoretical investigation of this question, and also

$a$ Wien: Ann. d. Phys., 44, p. 711; 1891. Dolezalek: Ann. d. Phys., 12, p. 1153; 1903. 
experimental measures, wherein the phase of the condenser current is shifted back by placing a resistance in series with it. Fortunately, the error due to the slight displacement of phase produced by the small absorption in a good mica condenser, is inappreciable. The effect of slight leakage is also investigated below, and proves to be inappreciable.

\section{CALCULATION OF THE EFFECT OF THE RESIDUAL INDUCTANCES AND CAPACITIES OF THE ARIS OF THE BRIDGE.}

Inductance in any arm of the bridge causes the current to lag, while capacity advances its phase. The angular lag due to an inductance $l$ is $\frac{p l}{R}$, and the angular advance due to capacity is $p c R$. The latter value follows from the fact that the capacity $c$ is in parallel with the resistance. The current through the resistance is $\frac{E}{R}$; the capacity current $90^{\circ}$ ahead of this is $p c E$. The ratio of these two currents is $p c R$, and this is the angle of advance of the resultant current. If $\frac{p l}{R}=p c R$, the current will have the same phase as though both capacity and inductance were absent. Thus, if $l=c R^{2}$ the coil may be considered free from inductance; if $l<c R^{2}$, it may be considered to possess negative inductance equal to $c R^{2}-l$.

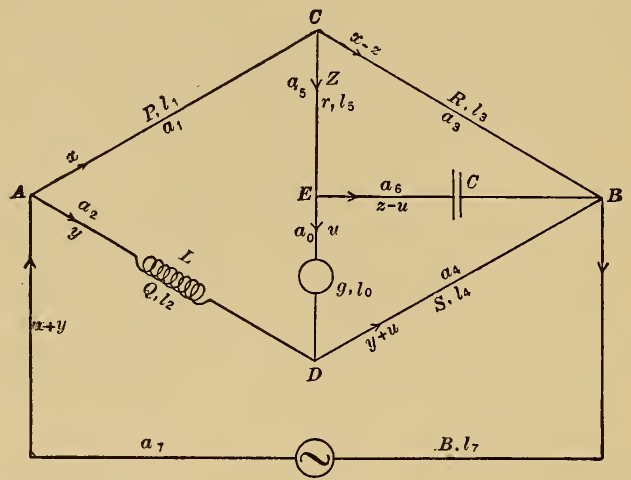

FIG. 7.-Network of Anderson Bridge, with currents, resistances, inductances, and impedances of the arms separately indicated.

The actual values of these residual positive or negative inductances vary widely, according to the length of wire on a coil, and its size, thickness of insulation, and manner of winding. High-resistance coils, made of many turns of fine wire wound in the usual noninductive manner, have relatively large capacity, which we here regard as negative inductance. In low-resistance coils of fewer turns of coarse wire the inductance predominates, and $l$ is therefore positive. 
To calculate the effect of these residual inductances, we shall form the equations for the networks of the Anderson bridge, assuming each branch to have positive or negative inductance, and solve for $L$ the inductance of the coil to be measured. In fig. 7 the resistances, inductances, impedances, and currents in each arm of the bridge are indicated, and the positive directions of the currents are shown by arrows. Thus,

g, $P, Q, R, S, r, 0, B$

$l_{0}, l_{1}, l_{2}, l_{3}, l_{4}, l_{5}, 0, l_{7}$

are the resistances.

$a_{0}, a_{1}, a_{2}, a_{3}, a_{4}, a_{5}, a_{6}, a_{7}$

are the small inductances, + or - .

$u, x, y, x-z, y+u, z, z-u, x+y$ are the currents.

The values of the impedances in the eight branches of the bridge are then as follows:

$$
\left.\begin{array}{l}
a_{0}=g+i p l_{0} \\
a_{1}=P+i p l_{1} \\
a_{2}=Q+i p\left(l_{2}+L\right) \\
a_{3}=R+i p l_{3} \\
a_{4}=S+i p l_{4} \\
a_{5}=r+i p l_{5} \\
a_{6}=0+\frac{1}{i p C} \\
a_{7}=B+i p l_{7}
\end{array}\right\}
$$

Applying Kirchhoff's law to the four circuits $A C D, C B E$, $E B D, A D B$, we have the following equations:

$$
\left.\begin{array}{l}
a_{1} x+a_{5} z+a_{0} u-a_{2} y=0 \\
a_{3}(x-z)-a_{6}(z-u)-a_{5} z=0 \\
a_{6}(z-u)-a_{4}(y+u)-a_{0} u=0 \\
a_{7}(x+y)+a_{2} y+a_{4}(y+u)=E
\end{array}\right\}
$$

Rearranging the terms of these equations, we have

$$
\left.\begin{array}{l}
a_{0} u+a_{1} x-a_{2} y+a_{5} z=0 \\
a_{6} u+a_{3} x-\left(a_{3}+a_{5}+a_{6}\right) z=0 \\
\left(a_{0}+a_{4}+a_{6}\right) u+a_{4} y-a_{6} z=0 \\
a_{4} u+a_{7} x+\left(a_{2}+a_{4}+a_{7}\right) y=E
\end{array}\right\}
$$

Solving for $u$, the current through the galvanometer, we obtain

$u=\frac{1}{\Delta}\left|\begin{array}{cccc}0 & a_{1} & -a_{2} & a_{5} \\ 0 & a_{3} & 0 & -\left(a_{3}+a_{5}+a_{6}\right) \\ 0 & 0 & a_{4} & -a_{6} \\ E & a_{7}\left(a_{2}+a_{4}+a_{7}\right) & 0\end{array}\right|=-\frac{E}{\Delta}\left|\begin{array}{ccc}a_{1} & -a_{2} & a_{5} \\ a_{3} & 0 & -\left(a_{3}+a_{5}+a_{6}\right) \\ 0 & a_{4} & -a_{6}\end{array}\right|$ 
If $u=0$, we then have

or,

$$
a_{1} a_{4}\left(a_{3}+a_{5}+a_{6}\right)-a_{3} a_{2} a_{6}+a_{3} a_{4} a_{5}=0
$$

$$
a_{1} a_{3} a_{4}+a_{1} a_{4} a_{5}+a_{1} a_{4} a_{6}+a_{3} a_{4} a_{5}-a_{2} a_{3} a_{6}=0
$$

Substituting the values of the impedances given in (5) above, we have

$$
\left.\begin{array}{c}
\left(P+i p l_{1}\right)\left(R+i p l_{3}\right)\left(S+i p l_{4}\right)+\left(P+i p l_{1}\right)\left(S+i p l_{4}\right)\left(r+i p l_{5}\right) \\
+\left(P+i p l_{1}\right)\left(S+i p l_{4}\right) \frac{1}{i p C}+\left(R+i p l_{3}\right)\left(S+i p l_{4}\right)\left(r+i p l_{5}\right) \\
-\left(Q+i p\left(l_{2}+L\right)\right)\left(R+i p l_{3}\right) \frac{1}{i p C}=0
\end{array}\right\}
$$

Separating the real and imaginary parts, we have first, for the real part

$$
\begin{aligned}
& P R S+P r S+R S r-\frac{L R}{C}+\frac{1}{C}\left[l_{1} S-l_{2} R-l_{3} Q+l_{4} P\right] \\
-p^{2} & {\left[r l_{4}\left(l_{1}+l_{3}\right)+S\left(l_{1} l_{3}+l_{1} l_{5}+l_{3} l_{5}\right)+R l_{4}\left(l_{1}+l_{5}\right)+P l_{4}\left(l_{3}+l_{5}\right)\right]=0 }
\end{aligned}
$$

Transposing and dividing by $\frac{R}{C}$,

$$
\left.\begin{array}{rl}
L= & C S\left[r\left(\frac{P+R}{R}\right)+P\right]+\frac{1}{R}\left[l_{1} S-l_{2} R-l_{3} Q+l_{4} P\right]- \\
& \frac{p^{2} C}{R}\left[r l_{4}\left(l_{1}+l_{3}\right)\right. \\
& \left.+S\left(l_{1} l_{3}+l_{3} l_{5}+l_{5} l_{1}\right)+R l_{4}\left(l_{1}+l_{5}\right)+P l_{4}\left(l_{3}+l_{5}\right)\right]
\end{array}\right\}
$$

or, if $L_{o}=C S\left[r\left(\frac{P+R}{R}\right)+P\right]$,

$$
L=L_{o}+\alpha-\beta
$$

If the small inductances $l_{1}, l_{2}, l_{3}, l_{4}, l_{5}$ are all zero, as in the ideal case, the last two terms disappear and

$$
L=C S\left[r \frac{(P+R)}{R}+P\right]
$$

and since in the Wheatstone bridge $\frac{P}{R}=\frac{Q}{S}$ we have

$$
L=C[r(Q+S)+P S],
$$

which is the expression (2) given above for the inductance by Anderson's method.

The last term $\beta$ in equation (12), having a coefficient $\frac{p^{2} C}{R}$ is negligible, unless the freauency is very high or the residual inductances excessive. 
The second term $\alpha$ gives the principal correction due to the inductances in the four arms of the bridge. It will be seen that the inductance of the resistance $r$ enters only in $\beta$, which is negligible when $l_{5}$ is small, and the galvanometer inductance has disappeared entirely from the equation. The second term $\alpha$ consists of four parts, two of which are positive and two negative. The part $\frac{1}{R}\left(l_{1} S-l_{3} Q\right)$, due to the two arms $P$ and $R$, is eliminated in our experiments by making $P=R$ and reversing $P$ and $R$. The remainder $\frac{1}{R}\left(l_{4} P-l_{2} R\right)=l_{4}-l_{2}$ (since $P=R$ ) is due to the two remaining arms $Q$ and $S$. As stated above, if these two arms consist of resistances made up of similar coils, (i. e., coils of the same resistance wound in the same manner with the same size wire) their inductances will be nearly equal. They might be exactly equal, if the inductive coil $L$ had no resistance. It is therefore desirable to have $l_{2}$ and $l_{4}$ as nearly equal as possible, and then when necessary apply a correction for their difference.

If we divide the expression for $\alpha$ in equation (11) above, by $Q$, remembering that $Q=\frac{P S}{R}$ (approximately), we obtain

$$
\begin{aligned}
\alpha & =Q\left[\frac{l_{1}}{P}-\frac{l_{2}}{Q}-\frac{l_{3}}{R}-\frac{l_{4}}{S}\right] \\
& =\frac{Q}{p}\left[\frac{p l_{1}}{P}-\frac{p l_{2}}{Q}-\frac{p l_{3}}{R}+\frac{p l_{4}}{S}\right] \\
& =\frac{Q}{p}\left[\phi_{1}-\phi_{2}-\phi_{3}+\phi_{4}\right]
\end{aligned}
$$

where $\phi_{1}, \phi_{2}, \phi_{3}, \phi_{4}$ are the phase angles of the currents in the four arms of the bridge, due to the combined inductance and capacity of the resistances $P, Q, R, S$, neglecting, of course, the inductance $L$ in $Q$, which is to be measured. These angles may be positive or negative. If they are all equal, or if $\phi_{1}+\phi_{4}=\phi_{2}+\phi_{3}$ (algebraically) the correction term reduces to zero.

As we shall show below, these angles are appreciable in the "6ninductive" windings usual in resistance boxes, and the correction $\alpha$ is therefore important in precision work. The resistances may, however, be so wound and adjusted as to make the angles $\phi$ inappreciable.

The imaginary part of equation (10) above gives

$$
\left.\begin{array}{c}
P S-R Q=p^{2}\left(l_{1} l_{4}-l_{3}\left(l_{2}+L\right)\right)+p^{2} C\left[P R l_{4}+S R\left(l_{1}+l_{5}\right)\right. \\
\left.+P S\left(l_{3}+l_{5}\right)+r\left(S l_{1}+S l_{3}+P l_{4}+R l_{4}\right)\right]-p^{4} C\left(l_{1} l_{3}+l_{3} l_{5}+l_{5} l_{1}\right) l_{4}=\gamma
\end{array}\right\}
$$

If $l_{1}, l_{2}, l_{3}, l_{4}, l_{5}$ are all zero, this reduces to $P S-R Q=0$, which is the 
condition for the Wheatstone bridge and the condition assumed in the ideal Anderson bridge. But when these quantities are not zero this condition does not hold and $Q$ is not equal to $\frac{P S}{R}$. Consequently, an error is introduced in calculating $L$ from the formula (2) of Anderson, unless $Q$ is assumed equal to $\frac{P S}{R}$, instead of using its actual value.

The variation of $Q$, due to changes in one or more of the small inductances $l$ ( $P, R$, and $S$ remaining unchanged), is illustrated in some of the examples given below.

\section{ILLUSTRATION OF THE FORMULE.}

In order to ascertain the order of magnitude of the corrections $\alpha$ and $\beta$ of formula (12), and the variation of $P S-R Q$ from zero in (15), we shall assume the following values of the constants for cases I, II, and III:

$$
\begin{aligned}
L & =1 \text { henry } \\
C & =1 \text { microfarad } \\
P & =R=250 \text { ohms, } \\
S & =500=Q \text { (approximately), } \\
r & =875, \\
p^{2} & =500,000 .
\end{aligned}
$$

Inductances in Microhenrys.

\begin{tabular}{c|c|c|c|c}
\hline \hline Case. & I & II & III & IV \\
\cline { 2 - 4 } & -2 & +25 & -50 & $-1,500$ \\
$l_{1}$ & +2 & +40 & +100 & -250 \\
$l_{2}$ & +2 & +25 & +50 & 0 \\
$l_{3}$ & -2 & +50 & -100 & $-5,000$ \\
$l_{4}$ & +10 & +50 & +100 & +100 \\
$l_{5}$ & + & &.+ \\
\hline
\end{tabular}

Case I is supposed to represent a specially wound bridge in which all the inductances are small, but in order to make it represent the most unfarorable case two are taken positive and two negative, so as to give a maximum value to the error $\alpha$.

Case II represents a favorable arrangement where the coils are similar and the inductances all positive, but with larger values than those of case I, being such as might be expected in practice.

In Case III we have assumed that $P$ is a single coil of fine wire, having the capacity effect greater than the inductance by an amount 
equivalent to a negative inductance of 50 microhenrys, whereas $R$ is made up of several coils of coarser wire, giving a smaller capacity and larger inductance, and hence $l_{3}$ is taken as +50 . Similarly, $S$ is supposed to be a single coil of $500 \mathrm{ohms}$, with capacity predominating, and equivalent to a negative inductance of 100 microhenrys, while $Q$ is the sum of several smaller coils, and $l_{2}$ is therefore positive and equal to 100 microhenrys. This is perhaps an extreme case, but not an improbable one.

In case IV larger resistances are assumed, viz:

$$
\begin{aligned}
P & =1,000=Q \text { (approximately). } \\
R & =S=5,000 . \\
r & =833.3 . \\
C & =0.1 \text { microfarad. }
\end{aligned}
$$

$P, Q$, and $S$ are assumed to have negative inductances, each being supposed to consist of a single coil (or mainly of large coils, as in the case of $Q$ ), while $R$ is supposed to be made up of smaller coils having the inductance and capacity balanced. The values of the inductances chosen for $P, Q$, and $S$ are approximately those found in noninductive

\begin{tabular}{|c|c|c|c|}
\hline Case. & $\mathrm{L}_{0}$ & $\alpha$ & $\beta$ \\
\hline I & 1 Henry & -0.000012 & $+\quad 4 \times 10^{-12}$ \\
\hline II & 1 " & +0.000010 & $-1.0 \times 10^{-8}$ \\
\hline III & 1 ، & -0.000400 & $+1.2 \times 10^{-8}$ \\
\hline IV & $1 ،$ & -0.002250 & $-34 \times 10^{-8}$ \\
\hline
\end{tabular}
resistances of such magnitudes.

Substituting the above values of the constants in equation (11) we find the following values of $\alpha$ and $\beta$ :

These results show that the $\beta$ term is small in comparison with $\alpha$, and may be neglected. The correction $\alpha$ is as large in case I as in Case II, showing that if the several small inductances are all of the same sign, and proportional to the resistances, they cancel out, except for the necessary inequality in $l_{2}$ and $l_{4}$, due to the resistance of the coil to be measured. If the inductances of the coils are adjusted to as small values as 2 microhenrys for each arm, they may be either positive or negative without making the error appreciable, as the error in case I, with $l_{1}$ and $l_{4}$ opposite in sign to $l_{2}$ and $l_{3}$ is the greatest possible for such values of $l_{1}, l_{2}, l_{3}, l_{4}$. 
The results shown in Table III illustrate the importance of the correction term $\alpha$ for coils of smaller inductances, namely: 100,10, 1, 0.1, and 0.01 millihenrys.

Table III.-Showing the Values of the Correction $\alpha$ for Various Values of Inductances and the Corresponding Values of Capacities and Resistances.

\begin{tabular}{|c|c|c|c|c|c|c|c|c|c|}
\hline $\begin{array}{c}\text { Induc- } \\
\text { tance to } \\
\text { be meas- } \\
\text { ured. }\end{array}$ & $\underset{\text { ity. }}{\text { Capac- }}$ & $P=R$ & $l_{1}$ & $l_{3}$ & $Q=S$ & $l_{2}$ & $l_{4}$ & $r$ & $\alpha$ \\
\hline $\begin{array}{l}\text { Milli- } \\
\text { henrys. }\end{array}$ & $\begin{array}{c}\text { Micro- } \\
\text { farads. }\end{array}$ & Ohms. & $\begin{array}{l}\text { Micro- } \\
\text { henrys. }\end{array}$ & $\begin{array}{l}\text { Micro- } \\
\text { henrys. }\end{array}$ & Ohms. & $\begin{array}{l}\text { Micro- } \\
\text { henrys. }\end{array}$ & $\begin{array}{l}\text { Micro- } \\
\text { henrys. }\end{array}$ & Ohms. & $\begin{array}{l}\text { Milli- } \\
\text { heniys. }\end{array}$ \\
\hline 100 & 1.0 & 250 & +2 & -2 & 250 & -2 & +2 & 75 & 0.008 \\
\hline 10 & 0.4 & 100 & +1 & -1.0 & 100 & -1 & +1 & 75 & 0.004 \\
\hline 1 & 0.1 & 50 & +0.5 & -0.5 & 100 & -1 & +1 & 25 & 0.004 \\
\hline 0.1 & 0.05 & 20 & +0.5 & -0.5 & 50 & -0.5 & +0.5 & 10 & 0.0045 \\
\hline 0.01 & 0.02 & 20 & +0.5 & -0.5 & 20 & -0.5 & +0.5 & 2.5 & 0.002 \\
\hline
\end{tabular}

It will be seen that the error $\alpha$ in the case of 100 millihenrys is scarcely appreciable, but that in the others it is appreciable and in the smaller coils it amounts to several per cent. These computed errors, as before, are the maximum values for the assumed residual inductances, since we have taken $l_{1}$ and $l_{4}$ of opposite sign to $l_{2}$ and $l_{3}$. In practice we should therefore expect smaller errors on the average unless the values of the $l$ 's are larger. If the coils are not wound to a minimum value of the inductance, the errors may be much larger than those above. It is therefore our practice in measuring small inductances to take them by difference, leaving $P, R$, and $S$ unchanged and altering $Q$ to compensate for the resistance of the coil to be measured. If the inductances of the resistances of $Q$, or at least of the part to be replaced by the coil to be measured, are accurately known, the difference of two determinations gives the true inductance desired.

The value of $P S-R Q$ is found from equation (15) by substituting the values of the resistances and residual inductances. In case $I$ above, $S-Q$ is only $-.003 \mathrm{ohm}$, while in Case $I V$ it is $-4.55 \mathrm{ohms}$. In other words, $Q$ is larger by $4.55 \mathrm{ohms}$ in a total of 1,000 when the bridge is exactly balanced for alternating current than it is for a direct-current balance. Consequently, if, as is sometimes done, the bridge is balanced with direct current, and then an alternating current is applied, the resistance balance no longer holds, if there are residual inductances and capacities, and $Q$ may require a change of several ohms to secure the resistance balance, the inductive balance being 
effected as we have seen above by varying $r$. In calculating $L$, however, no account need be taken of $Q$, as it is eliminated from the expression (13) for $L$. Hence there is no occasion to calculate the value of $\gamma$ in (15).

\section{EFFECT OF RESISTANCE IN SERIES AND IN PARALLEL WITH THE CONDENSER.}

As a mica condenser is not entirely free from absorption and might also show slight leakage, it is desirable to ascertain how large an error, if any, is produced by using such a condenser instead of the ideal condenser assumed in the theory of the Anderson bridge, namely, one in which the impedance is $\frac{1}{i p C}$. Resistance in series with a perfect condenser produces the same phase displacement as a certain amount of absorption, and resistance in parallel with the condenser has the effect of leakage or imperfect insulation. In a good mica condenser the

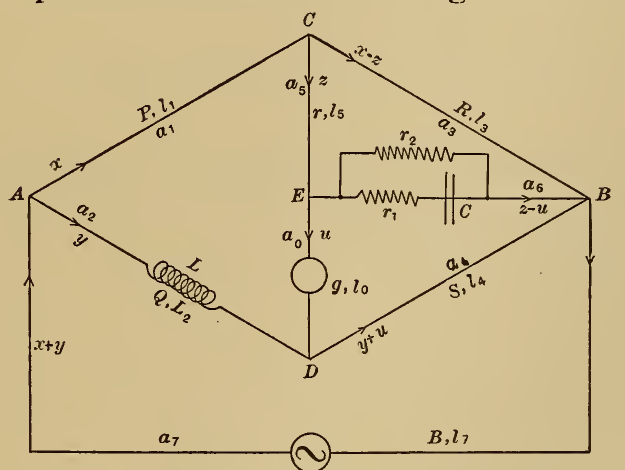

FIG. 8.-Resistance in series and in parallel with the condenser.

phase of the current with a frequency of 100 per second should differ from quadrature with the electromotive force by not more than one minute of angle, and may be as small as $30^{\prime \prime}$, although it may be several minutes in inferior condensers (even as high as $30^{\prime}$ ). For paper condensers the angle may be as small as $4^{\prime}$ and as large as several degrees. For a condenser of one microfarad capacity, with a frequency of 100 per second, $30^{\prime \prime}$ of angle corresponds to a resistance in series with the condenser of $0.23 \mathrm{ohm}$, whereas $30^{\prime}$ would correspond to a resistance of 14 ohms.

In other words, such resistances in series with perfect condensers would give currents of the same phases as the imperfect condensers employed. A leakage resistance less than a thousand megohms would never occur in a good condenser. We shall now calculate (1) the effect 
of introducing resistance in series with the condenser to correspond with absorption and (2) of placing a high-resistance shunt around the condenser to represent leakage. In fig. 8 these two resistances are represented by $r_{1}$ and $r_{2}$. If we substitute the values of the impedances of the arms of the bridge in formula (9), we shall obtain an expression for the inductance to be measured in the same manner as before. In this case, however, we assume for convenience that the resistances $P, Q, R, S$, and $r$ are all free from inductance or capacity (except, of course, $L$ in $Q$ ), and hence

$$
\begin{aligned}
& a_{1}=P \\
& a_{2}=Q+i p L \\
& a_{3}=R \\
& a_{4}=S \\
& a_{5}=r \\
& a_{6}=r_{1}+\frac{1}{i p C} \text { in the first case, } \\
& a_{6}=\frac{r_{2}}{1+i p C r_{2}} \text { in the second case. }
\end{aligned}
$$

and

(a) Resistance in series with the condenser.-Equation (9) becomes, when the above values of the impedances are substituted,

$$
P R S+P S r+P S\left(r_{1}+\frac{1}{i p C}\right)+R S r-(Q+i p L)\left(r_{1}+\frac{1}{i p C}\right) R=0
$$

Separating the real and imaginary parts, we have, first, for the real part,

or,

$$
\begin{aligned}
& P S\left(R+r+r_{1}\right)+R S r-Q R r_{1}-\frac{L}{C} R=0 \\
& L=C S\left[r \frac{(P+R)}{R}+P\right]+C r_{1}\left[\frac{P S}{R}-Q\right]
\end{aligned}
$$

The first term of this expression is the same as that of (13), and is the value of $L$ when $r_{1}$ is zero. $\frac{P S}{R}-Q$ would be zero in the ideal bridge. To find its value in this case we make use of the imaginary part of (16) above.

This imaginary part is

or,

Whence

$$
\begin{aligned}
& \frac{P S-R Q}{i p C}-i p L R r_{1}=0 \\
& P S-R Q=-p^{2} L R r_{1} C . \\
& Q=\frac{P S}{R}+p^{2} L r_{1} C .
\end{aligned}
$$


Substituting the value of $\frac{P S}{R}-Q$, derived from (18), in equation (17), we have

$$
L=C^{\gamma} S\left[r \frac{(P+R)}{R}+P\right]-p^{2} r_{1}^{2} L C^{2}
$$

In fig. 9 , which is the impedance diagram of a condenser, $r_{1}$ is the series resistance, equivalent (in its effect upon the phase angle) to the absorption, and $\theta$ is the small angle by which the current falls short of $90^{\circ}$ in its phase relation to the impressed electromotive force. Hence $\tan \theta=p C r_{1}$. Substituting in (19) above,

or,

$$
\begin{aligned}
& L=L_{0}-L \tan ^{2} \theta \\
& L=L_{0}\left(1-\tan ^{2} \theta\right)
\end{aligned}
$$

since $L_{0}$, the value of $L$ when the correction is zero, is substantially the same as $L$. In the best mica conperfect condenser. densers, as stated above, $\theta$ is about half a minute, and $\tan \theta$ is $0.00015 ; \tan ^{2} \theta$ is therefore only about two parts in a hundred million. Hence the angle $\theta$ might be ten times as large without producing an appreciable error, although in some mica condensers that we have tested the angle is large enough to produce a sensible error.

(b) Resistance in parallel with the condenser. - Substituting $\frac{r_{2}}{1+i p C r_{2}}$ for $a_{6}$ in equation (9) above, we get a solution for the case of resistance in parallel with the condenser. The direct substitution gives

$$
P R S+P S r+P S\left(\frac{r_{2}}{1+i p C r_{2}}\right)+R S r-R(Q+i p L)\left(\frac{r_{2}}{1+i p C r_{2}}\right)=0
$$

The real part of this is

$$
\begin{gathered}
P R S+P S r+R S r+(P S-R Q) r_{2}=0 \\
\text { Hence, } \quad Q-\frac{P S}{R}=\frac{S}{r_{2}}\left[r \frac{(P+R)}{R}+P\right] \\
\text { or, } \\
Q-\frac{P S}{R}=\frac{L_{0}}{r_{2} C}
\end{gathered}
$$

Thus, the variation in $Q$ is inversely proportional to $r_{2}$, the shunt resistance, and to the capacity of the condenser, and directly proportional to $L$. The leakage resistance through a condenser is inversely proportional to the capacity, so that in general $r_{2} C$ is independent of the value of the capacity, but depends on the quality of the condenser. 
If $r_{2}=1000$ megohms and $C=1$ microfarad, $r_{2} C=1000$ and the variation of $Q$ is in that case very small.

The imaginary part of equation (21) above is

or,

$$
C r_{2}(P R S+P S r+R S r)=L r_{2} R
$$

$$
L=C S\left[r \frac{(P+R)}{R}+P\right]=L_{\mathrm{o}}
$$

This is equation (13), and shows that $r_{2}$ has no effect whatever on the measured value of $L$.

\section{VERIFICATION OF FORMULAE 11, 18, 19, 22, 23.}

In Table IV the results are given of a series of measurements made to verify formula (11) by introducing a small inductance successively in each of the arms of the bridge; the $\beta$ term in this formula is negligible, in comparison with $\alpha$, except for the case of inductance in $r$ only, in which case $\alpha$ is zero and the $\beta$ term has then been computed. This is the fifth case in the table, where the observed change $(\Delta \beta$ in this case, as $\Delta \alpha=0$ ) is 0.01 millihenry, whereas the calculated effect is still smaller. But the inductance coil measured has an inductance of 1 henry, and hence the observed change is only one part in a hundred thousand, a quantity barely measureable.

If we differentiate formula (12) we have, since $L$ does not change when the inductance coil is inserted in any arm of the bridge, and $\beta$ is assumed zero,

or,

$$
\begin{aligned}
& \Delta L_{\mathrm{o}}+\Delta \alpha=0 \\
& \Delta \alpha=-\Delta L_{\mathrm{o}}
\end{aligned}
$$

where $\Delta \alpha$ is the change produced in the $\alpha$ term by the insertion of the given coil in any arm of the bridge, and $\Delta L_{\mathrm{o}}$ is the change in the first term of equation (11) or (12); that is, in the computed value of $L$ apart from the correction terms.

For example, in the first case, 0.5 millihenry was inserted in the arm $Q$, and hence $l_{2}$ was increased by 0.5 millihenry. The second term of the $\alpha$ correction was therefore increased by $0.5 \times \frac{R}{R}=0.500$ millihenry. The observed value of $\Delta L_{\mathrm{o}}$ in this case was the same. In case 3, the addition of 0.5 millihenry in $P$ changed the first term of the $\alpha$ correction by $0.5 \times \frac{S}{R}=1.000$ millihenry, whereas the measured change was 0.999 millihenry. In the fourth case the difference 


\begin{tabular}{|c|c|c|c|c|c|c|c|}
\hline & $=$ & 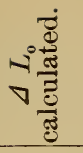 & 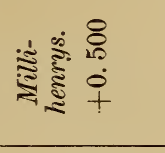 & $\begin{array}{l}8 \\
0 \\
0 \\
0 \\
i\end{array}$ & $\begin{array}{l}8 \\
\dot{8}\end{array}$ & $\begin{array}{l}8 \\
\dot{+}\end{array}$ & $\begin{array}{l}\text { \&े } \\
\dot{8} \\
\dot{0}\end{array}$ \\
\hline & 어 & 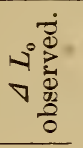 & 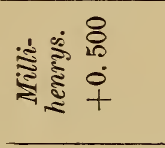 & $\begin{array}{l}\frac{0}{10} \\
\dot{0} \\
1\end{array}$ & $\begin{array}{l}\mathscr{8} \\
\dot{\Phi} \\
\dot{0}\end{array}$ & $\begin{array}{l}8 \\
80 \\
0 \\
+\end{array}$ & $\begin{array}{l}\circ \\
0 \\
0 \\
+\end{array}$ \\
\hline & $\theta$ & $\frac{2}{\nabla}$ & $\stackrel{\dot{\Xi}}{\tilde{\Xi}} 0$ & 0 & $\begin{array}{l}+ \\
⿱ 亠 䒑 \\
0 \\
+ \\
+\end{array}$ & 0 & 0 \\
\hline $\bar{b}$ & $\infty$ & $\frac{2}{\nabla}$ & $\stackrel{\dot{\Xi}}{\stackrel{\Xi}{0}} 0$ & 0 & 0 & 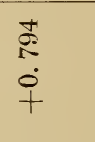 & 0 \\
\hline 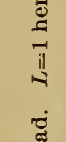 & $N$ & $\nabla$ & हैं & $\begin{array}{l}\mathscr{2} \\
\dot{0} \\
+\end{array}$ & 0 & 0 & 0 \\
\hline 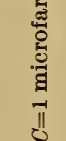 & 0 & $\dot{\nabla}$ & $\begin{array}{l}\dot{0} \\
\stackrel{9}{+} \\
\stackrel{0}{0}\end{array}$ & 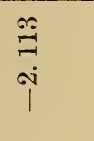 & $\begin{array}{l}8 \\
\substack{1 \\
\text { i } \\
1}\end{array}$ & $\begin{array}{l}\hat{\infty} \\
\therefore \\
\stackrel{0}{+} \\
+\end{array}$ & $\begin{array}{l}\stackrel{0}{0} \\
\dot{0} \\
+\end{array}$ \\
\hline $\begin{array}{l}\dot{\text { g }} \\
\text { : } \\
\dot{0} \\
\text { o. } \\
\text { II } \\
\text { b }\end{array}$ & 10 & $=\underset{\Xi}{\stackrel{\Xi}{\sharp ~}}$ & 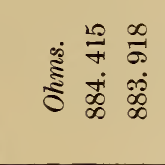 & $\begin{array}{ll}\mathscr{N} & \mathscr{8} \\
\infty & \infty \\
\dot{\infty} & \infty \\
\infty & \infty\end{array}$ & 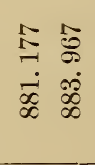 & $\begin{array}{ll}\overrightarrow{1} & \hat{8} \\
\infty & 8 \\
0 & \infty \\
\infty & \infty \\
\infty & \infty\end{array}$ & $\begin{array}{ll}8 & 08 \\
\mathscr{8} & : 8 \\
\infty & \infty \\
\infty & \infty \\
\infty & \infty\end{array}$ \\
\hline 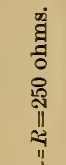 & $\pi$ & 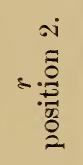 & 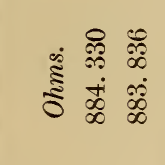 & 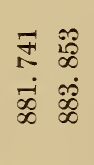 & $\begin{array}{ll}\vec{H} & \approx \\
\infty & \infty \\
\dot{0} & \infty \\
\dot{\infty} & \infty \\
\infty & \infty\end{array}$ & $\begin{array}{ll}\infty & \mathscr{0} \\
\infty & \infty \\
\infty & \infty \\
\dot{\infty} & \infty \\
\infty & \infty \\
\infty & \infty\end{array}$ & $\begin{array}{ll}\infty & \infty \\
\infty & \infty \\
\infty & \infty \\
\infty & 0 \\
\infty & 0 \\
\infty & \infty\end{array}$ \\
\hline & $\infty$ & $=\frac{\dot{0}}{\stackrel{0}{\tilde{0}}}$ & 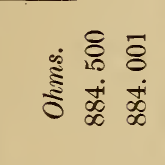 & $\begin{array}{ll}\vec{\sigma} & \stackrel{1}{0} \\
\dot{\sigma} & + \\
\dot{\infty} & \infty \\
\infty & \infty\end{array}$ & \begin{tabular}{ll}
$\stackrel{5}{5}$ & 5 \\
\multirow{2}{*}{} & 8 \\
$\dot{\infty}$ & + \\
$\infty$ & $\infty$ \\
$\infty$ & $\infty$
\end{tabular} & 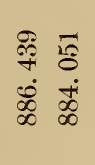 & 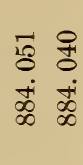 \\
\hline & N & $\begin{array}{l}\dot{\overline{0}} \\
\overrightarrow{0} \\
\tilde{0} \\
\stackrel{0}{0} \\
\stackrel{0}{0}\end{array}$ & $\begin{array}{ll} & 0 \\
& 0 \\
0 & 0 \\
0 & 0 \\
0 & 0 \\
\overline{8} & \overline{8} \\
\overline{8}\end{array}$ & 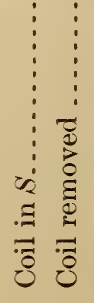 & 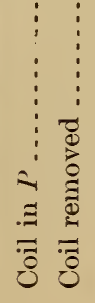 & 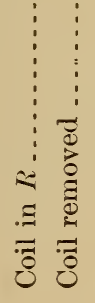 & 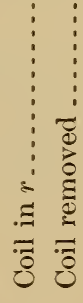 \\
\hline & -1 & $\dot{0}$ & - & N & $\therefore$ & $\theta$ & 10 \\
\hline
\end{tabular}


between the observed and calculated value was larger, namely, 0.011 millihenry. This is, however, only 11 parts in a million compared with the coil being measured, and is a very small discrepancy. These results may be regarded as fully verifying the formula when the inductances are positive.

Table V.-Effect of placing a Capacity of 0.00945 Microfarad in Paraliel with the Arus of the Anderson Bridge.

[P=R=250 ohms. $S=500$ ohms. $C=1$ microfarad. $L=1$ henry. $]$

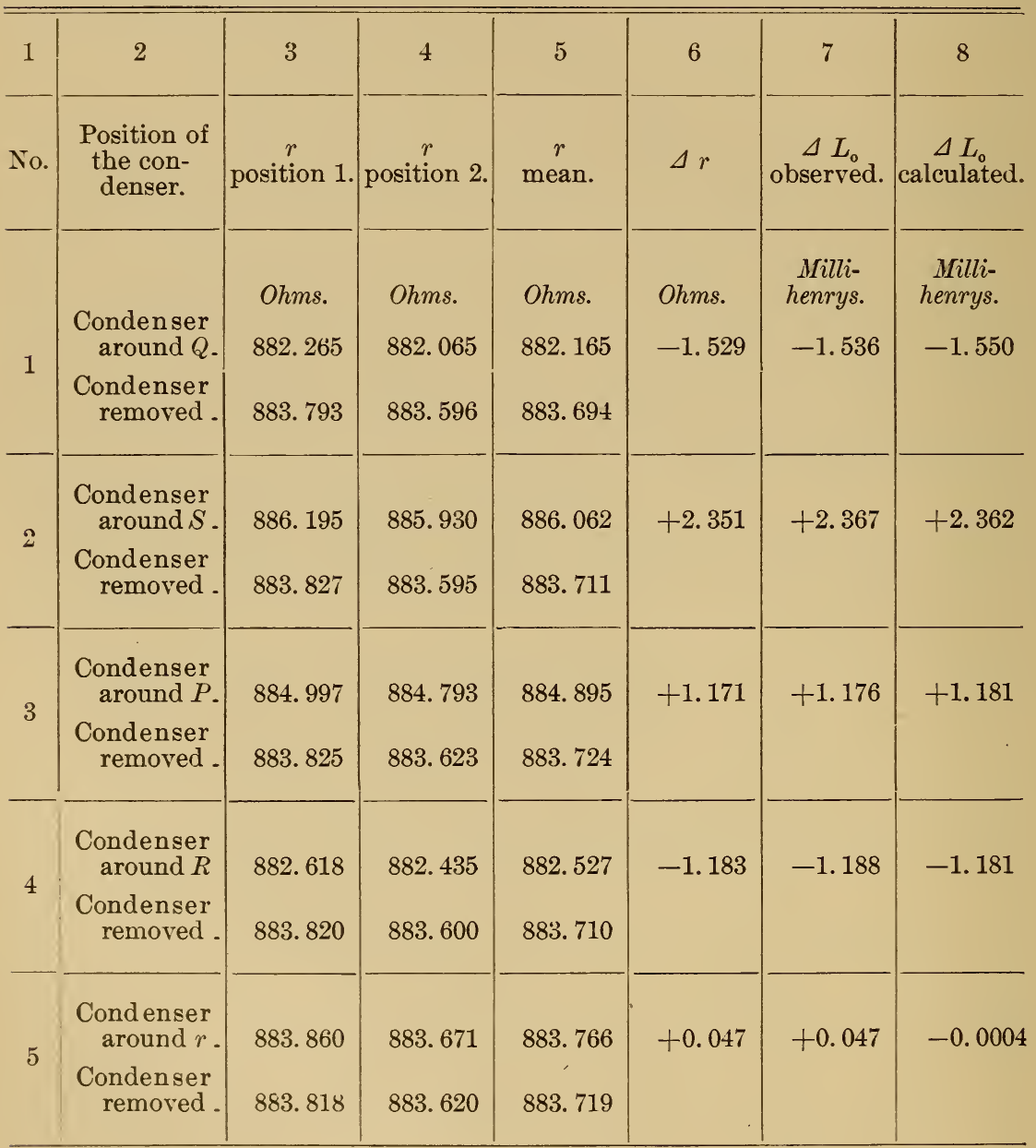


In the columns headed $\Delta S, \Delta R, \Delta P$, the quantity 0.794 represents the resistance of the inductance coil of 0.5 millihenry inserted in the arms.

To test the formula for the case of negative inductances, a capacity was inserted in parallel with each of the five arms of the Anderson bridge in succession, and the changes in $r$ observed. From these changes $\Delta L_{\mathrm{o}}$ was determined and the result compared with the computed change in the $\alpha$ correction term. As stated above, a capacity $C$ placed in parallel with a resistance $R$ is equivalent to a negative inductance $l$, determined by the expression

$$
l=C R^{2}
$$

This capacity may be located in the resistance coil itself or in a condenser joined in parallel with it.

In the first case of Table $V$ the resistance of $Q$ was 405 ohms noninductive and $95 \mathrm{ohms}$ in the coil whose inductance was 1 henry. The condenser was placed in parallel with the former, and had an effect proportional to $\overline{405}^{2}$ as compared with an effect proportional to $\overline{500}^{2}$ in $S$, given in case 2. It will be seen that the differences between the observed and calculated changes, due to capacity, is only a few thousandths of a millihenry - that is, only a few parts in a million of the coil each time measured. Hence the formula may be regarded as completely verified for negative inductances as well as positive.

Table VI.-Effect of Placing Resistance $r_{1}$ in Series With the Condenser of the Anderson Bridge.

[ $P=R=250$ ohms. $S=250$ ohms. $L=1$ henry. $C=2$ microfarads. $p^{2}=474,800 . \quad n=110$ per second.]

\begin{tabular}{|c|c|c|c|c|c|c|c|c|}
\hline 1 & 2 & 3 & 4 & 5 & 6 & 7 & 8 & 9 \\
\hline$r_{1}$ & $\begin{array}{c}r \\
\text { Position } 1 .\end{array}$ & $\begin{array}{c}r \\
\text { Posi- } \\
\text { tion } 2 .\end{array}$ & $\begin{array}{c}r \\
\text { Mean. }\end{array}$ & $\Delta L_{\mathrm{o}}$ & $p^{2} r_{1}^{2} C^{2} L$ & $Q^{\prime}$ & $\triangle Q$ & $p^{2} r_{1} C L$ \\
\hline $\begin{array}{c}\text { Ohms. } \\
0\end{array}$ & $\begin{array}{l}\text { Ohms. } \\
871.82\end{array}$ & $\begin{array}{l}\text { Ohms. } \\
871.59\end{array}$ & $\begin{array}{c}\text { Ohms. } \\
871.705\end{array}$ & $\begin{array}{l}\text { Milli- } \\
\text { henrys. }\end{array}$ & $\begin{array}{c}\text { Milli- } \\
\text { henrys. }\end{array}$ & $\begin{array}{l}\text { Ohms. } \\
155.27\end{array}$ & Ohms. & Ohms. \\
\hline 5 & 871.89 & 871.68 & 871.785 & +0.08 & +0.05 & $\ldots$ & …..... & .. \\
\hline 20 & 872.625 & 872.40 & 872.51 & 0.80 & 0.76 & 173.86 & +19.43 & +19.00 \\
\hline 40 & 874.92 & 874. 72 & 874.82 & 3.12 & 3.05 & 189.80 & 35.78 & 38.00 \\
\hline 80 & 884.07 & 883.98 & 884.025 & 12.32 & 12.19 & 225.99 & 72.39 & 76.00 \\
\hline 0 & & & & & & 153.18 & & \\
\hline
\end{tabular}

Table VI gives the results of measurements made to verify formulæ (18) and (19). Resistances of 5, 20, 40, and 80 ohms were placed in 
BULLETIN OF THE BUREAU OF STANDARDS. [Vol.1, No.3.

\begin{tabular}{|c|c|c|c|}
\hline$=$ & 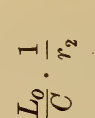 & 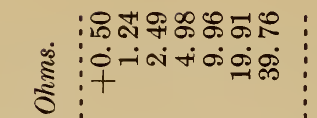 & 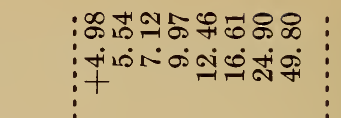 \\
\hline$\subseteq$ & $\begin{array}{l}\otimes \\
\nabla\end{array}$ & 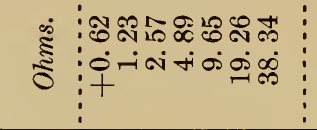 & 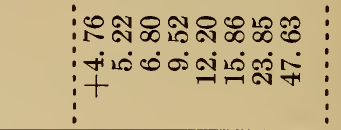 \\
\hline$\infty$ & خे & 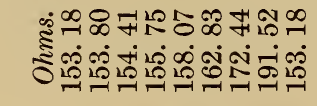 & 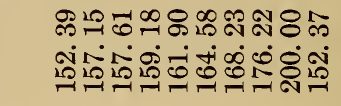 \\
\hline$\propto$ & 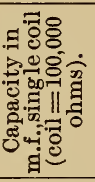 & 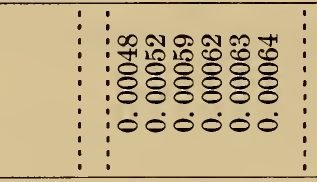 & 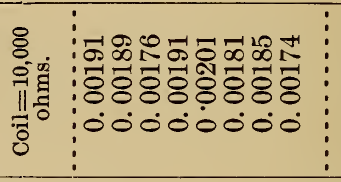 \\
\hline$\wedge$ & $\begin{array}{l}\frac{0}{\delta} \\
0\end{array}$ & 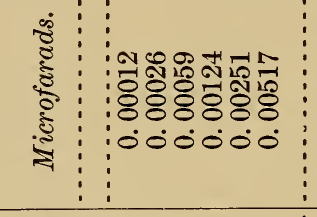 & 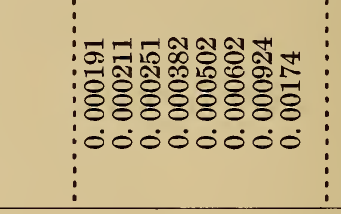 \\
\hline 0 & Nolo & 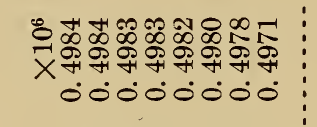 & 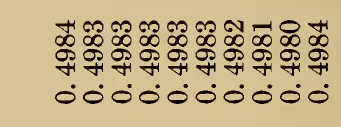 \\
\hline 10 & $\frac{1}{2}$ & 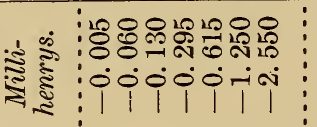 & 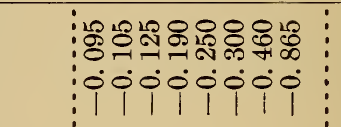 \\
\hline+ & $=-\overbrace{}^{\mathbb{E}}$ & 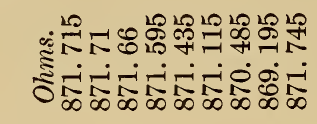 & 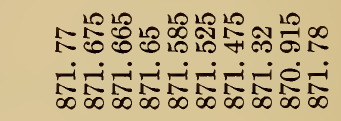 \\
\hline$\infty$ & 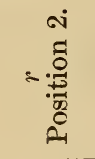 & 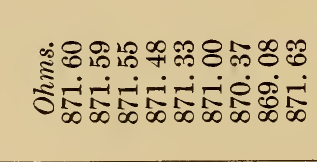 & 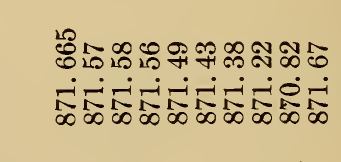 \\
\hline N & 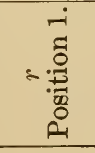 & 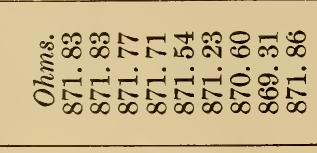 & 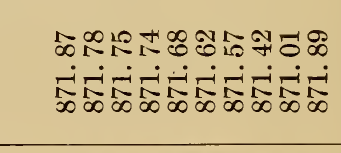 \\
\hline$\neg$ & $=$ & 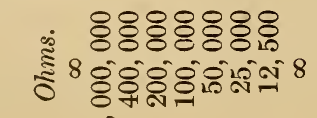 & 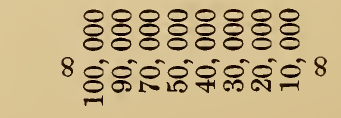 \\
\hline
\end{tabular}


succession in series with the condenser, the latter having a capacity of 2 microfarads. The changes in $r$ were determined as before, and the changes in $L_{\mathrm{o}}$ resulting therefrom were computed, and these compared with $p^{2} r_{1} C^{2} L$ (formula 19). The changes in $Q$ were computed from equation (18) and compared with the changes in the noninductive part of the arm Q, namely, $Q^{\prime}$.

These measurements were made before the introduction into the bridge of the slide wire, which permits settings to $0.001 \mathrm{ohm}$, and hence were not quite as accurate as those previously given. Nerertheless the agreement between the observed and calculated values is excellent.

Table VII gives the results of measurements made to verify formulæ 22 and 23. Two series of measurements were made. In one a megohm box, consisting of 10 coils of 100,000 ohms each, was used to give resistances varying from $1,000,000$ to $12,500 \mathrm{ohms}$, using various combinations of coils in series and in parallel. In the other a box of 10 coils of 10,000 ohms each was used, the coils being used in series only. In both cases the capacity of the coils produces a distinct effect on the measured value of $L_{o}$, and hence we have assumed formula (23) to be correct and have calculated the values of the capacities of the coils, which will account for the differences observed. They are given in the seventh column, and the capacity of one coil deduced from the measured capacity of the several coils is given in the eighth column. These deduced capacities per coil, averaging 0.00186 microfarad in the case of the second box, agrees quite well with an independent measurement made some months ago by a dynamometer method which gave 0.00195 microfarad for the average. It will be noticed that the changes in $Q$ are considerable and that the observed and calculated values agree quite closely. These differences, however, can not be determined with great accuracy, as the resistance of the inductive coil (wound with copper wire) varies from time to time; hence $Q^{\prime}$ varies from this cause when $Q$ is constant. The results, however, abundantly justify the formulæ (22 and 23).

\section{GRAPHICAL SOLUTION OF THE ANDERSON BRIDGE.}

A graphical solution of Anderson's bridge is interesting and shows very simply some of the results derived above analytically. If the bridge is balanced and no current is flowing through the galvanometer, we may consider that the connection $E D$ is removed. The condition of the bridge is (the same electromotive force acting on the upper half of the bridge from $A$ to $B$ as on the lower half) that $E$ and $D$ are always at the same potential.

To construct the electromotive-force diagram for the upper half of the bridge, we lay off $C B$ (fig. 11) to represent the emf. acting on the 
arm $R$ of the bridge. The same electromotive force acts on the branches $C E B$, consisting of the resistance $r$ and the condenser of impedance $\frac{1}{p C}$. Therefore, in a semicircle described on $C B$ as a diameter construct a right-angled triangle $C E B$, the sides $C E$ and $B E$ being proportional to $r$ and $\frac{1}{p C}$, respectively. $C E$ is then equal to $e_{5}$, the emf. acting on $r$, the fifth arm of the bridge, and $E B=e_{6}$,

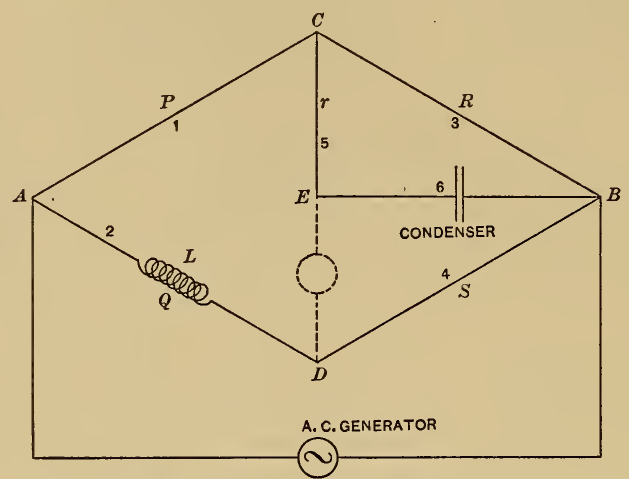

Fig. 10.-Anderson Bridge. When balanced, galvanometer may be removed.

the emf. on the condenser. $C c^{\prime}$ and $C b$ are the currents in $r$ and $R$, respectively (calculated from the electromotive forces and resistances), and their resultant $C b^{\prime}$ equals the current in the arm $P$-that is, $i_{1}$. Of course $i_{5}$ is also the current through the condenser. The emf. acting on the arm $P$ is in phase with the current. $C b^{\prime}$, since $P$ is noninductive. Therefore, if we project $C b^{\prime}$ backward to $A$, so that

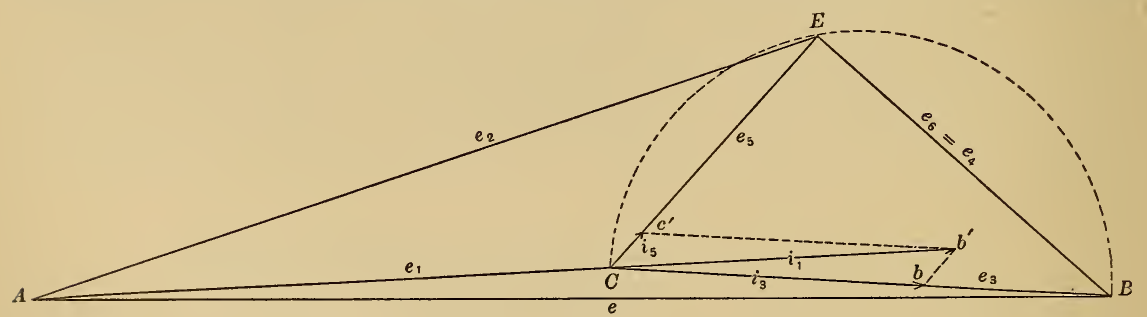

FIG. 11.-Vector diagram of Anderson Bridge.

$C A=i_{1} \times P, C A$ is the emf. $e_{1}$ acting on $P$, and the vector sum of $A C$ and $C B$, or $A B$, will be the total emf. on the bridge.

Since the lower half of the bridge has the same emf. acting on it and the point $D$ has the same potential as $E$, it is evident that the triangle $A E B$ is also the emf. triangle of the lower half $A D B$. This enables us to find graphically the inductance $L$ in the branch $Q$. 
Lay off $D B$ (fig. 12) equal to $E B$ (fig. 11), since the same emf. acts on these two branches, which terminate at the common point $B$, their initial ends $E$ and $D$ having the same potential. Draw lines $D A$ and $B A$ so that the triangle $A D B$ is equal to the triangle $A E B$ of fig. 11. $A D B$ is then the emf. triangle of the lower half of the bridge, and $A D$ is the emf. $e_{2}$ expended on the branch $Q$. Of this, $D G$, perpendicular to $D B$, overcomes the reactance $p L$, and $A G$, perpendicular to $D G$, overcomes the resistance $Q$. This construction gives $L$ when $p$ is known.

But $p$ need not necessarily be known, as the values of the capacity and resistances of the bridge are independent of $p$. The distribution

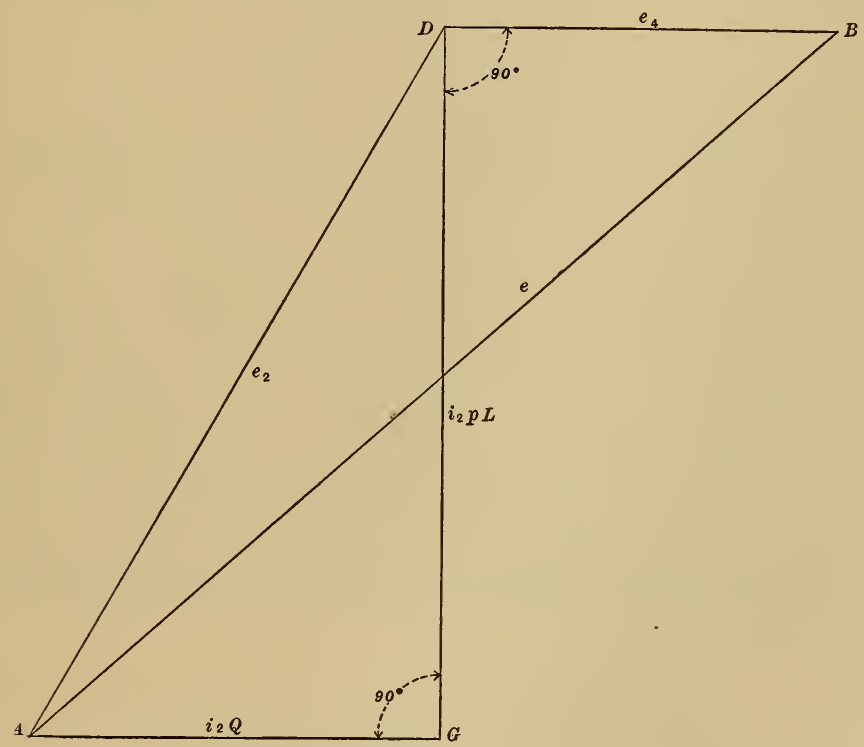

FIG. 12.-Graphical solution of Anderson Bridge.

of electromotive forces is, however, affected by the frequency, and hence the emf. triangle depends on $p$. If, however, any convenient value of $p$ be assumed in constructing figures 11 and 12, the same value of $L$ will be derived from $D G$; that is, $D G$ will always come out proportional to $p$.

The inductance $L$, derived from $D G$, is the total inductance of the branch $Q$; hence, if that part of the resistance of $Q$ not included in the inductance coil to be measured possesses positive or negative inductance $\left(l_{2}\right)$, this must be subtracted from the measured value $\left(L_{0}\right)$ to obtain the true inductance of the coil $L$.

If the branch $S$ contains inductance $l_{4}, D B B^{\prime}$ will be its voltage 2214-No. 3-05-3 
triangle, and the angle $\phi_{4}$ will be $\frac{p l_{4}}{S}$. The triangle $A D B$, which still represents the distribution of voltages, both in the upper and lower

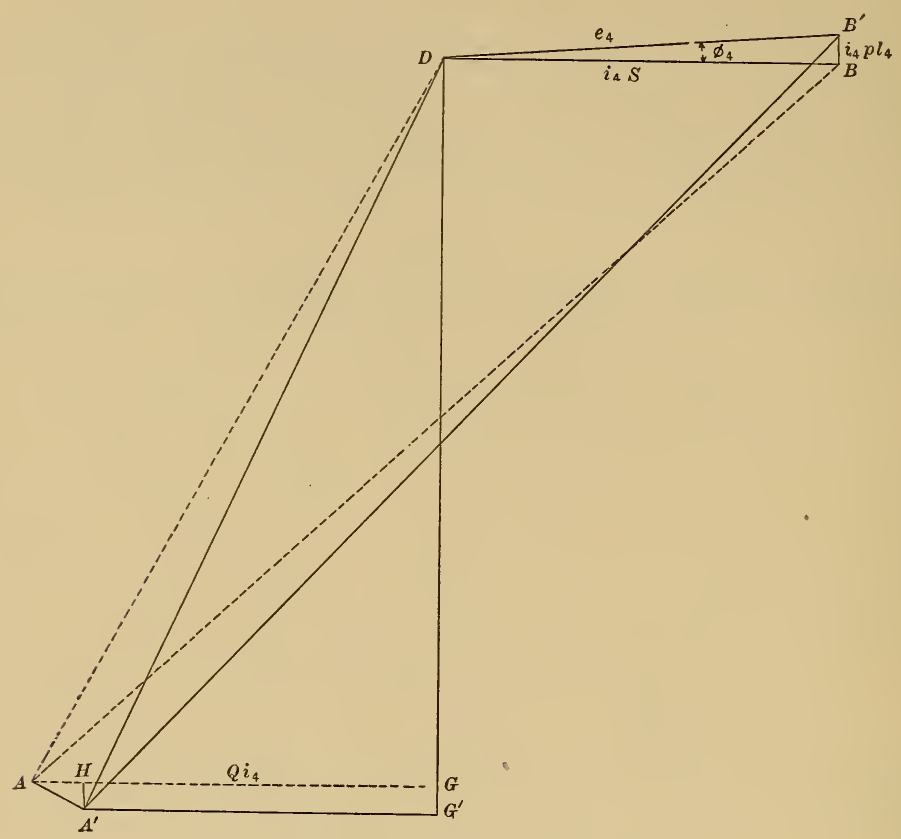

FIG. 13.-Solution when arm $S$ has inductance $l_{4}$.

halves of the bridge, will therefore be rotated through the angle $\phi_{t}$ into the position $A^{\prime} D B^{\prime}$, where

$$
\begin{aligned}
A A^{\prime} & =A D \times \phi_{4} \\
A^{\prime} H & =A A^{\prime} \sin A^{\prime} A H=A A^{\prime} \sin A D G \\
\text { Hence, } G G^{\prime} & =A D \times \phi_{4} \times \frac{A G}{A \nu}=\phi_{4} \times Q i_{4}=\Delta(p L) i_{4} \\
\therefore \quad \Delta L & =\frac{Q}{p} \phi_{4}=\frac{l_{4}}{S} Q .
\end{aligned}
$$

This is the value of the correction due to $l_{4}$ found above analytically and given by equations (11) and (14), neglecting small quantities of the second order occurring in the $\beta$ term. A similar construction obviously applies to the case of capacity in the resistances; that is, to negative inductance.

\section{RESISTANCE IN SERIES AND IN PARALLEL WITH THE CONDENSER.}

Fig. 14 is the electromotive-force diagram for the Anderson bridge on which 100 volts is impressed, the frequency being such that 
$p^{2}=500,000$ and $p=707$, approximately, and fig. 15 is the corresponding case, with 50 ohms inserted in series with the condenser. $C F$ now represents the fall in potential through $r$ and $r_{1}$ (fig. 8); but since the galvanometer is joined to $E$, between $r$ and $r_{1}$, the triangle $A E B$, and not $A F B$, represents the electromotive forces of the lower half of the bridge. The values of the several electromotive forces and currents have been accurately calculated from formula (19) and marked in the figures. The effect of inserting $r_{1}$ in the condenser circuit is to

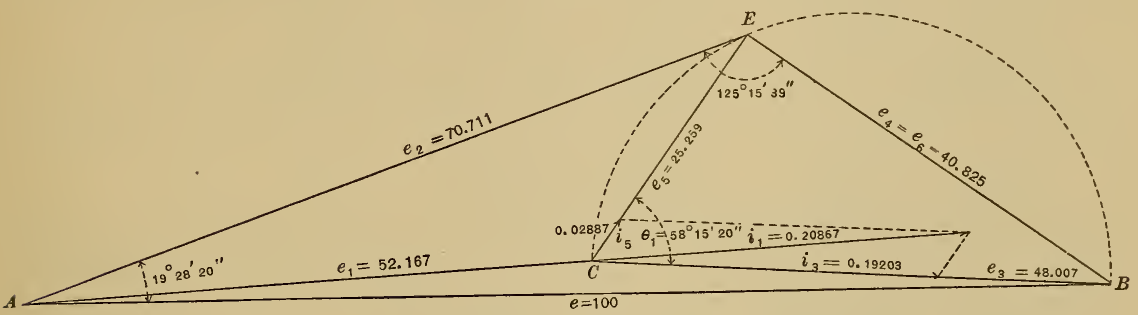

Fig. 14.-Electromotive force diagram of Anderson Bridge, having 100 volts applied to terminals.

decrease the currents $i_{3}$ and $i_{5}$. Their resultant, however, is increased, as the angle $\theta_{1}$ between them is decreased sufficiently to more than offset the decrease in the separate currents. The current $i_{1}$ is therefore increased, and $e_{1}$ is increased in consequence. The side $E B$, the fall in potential in $S$, is decreased. This shows that the current in the lower half of the bridge is decreased, since $S$ is noninductive. But $A E$, the emf. on $Q$, is increased; and since the current through $Q$ is decreased, it follows that the impedance, and therefore the resist-

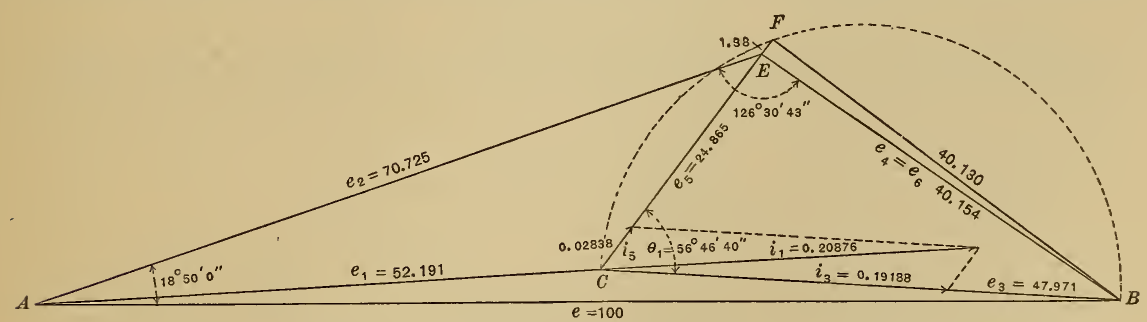

Fig. 15.-Case of Fig. 14 modified by $50 \mathrm{ohms}$ resistance in series with the condenser.

ance, is increased, as is found in practice. In this case $Q$ changes from 500 to 525 ohms. The change in $r$ is very slight-in this case from 875 to 876.25 . The change in $L_{o}$ is also very slight. Its value is given by equation (19), but can not be deduced easily geometrically.

Fig. 17 shows the effect of placing 10,000 ohms in parallel with the condenser. In this case the current $i_{5}$ through $r$ splits into two parts, 
$i_{6}$ through the condenser and $i_{7}$ through $r_{2}$, these two components being at right angles to each other. The result is to reduce the voltage on the condenser, and hence also the current through the condenser. The current $i_{5}$ (the sum of $i_{6}$ and $i_{7}$ ) is less than before, and $i_{3}$ is also

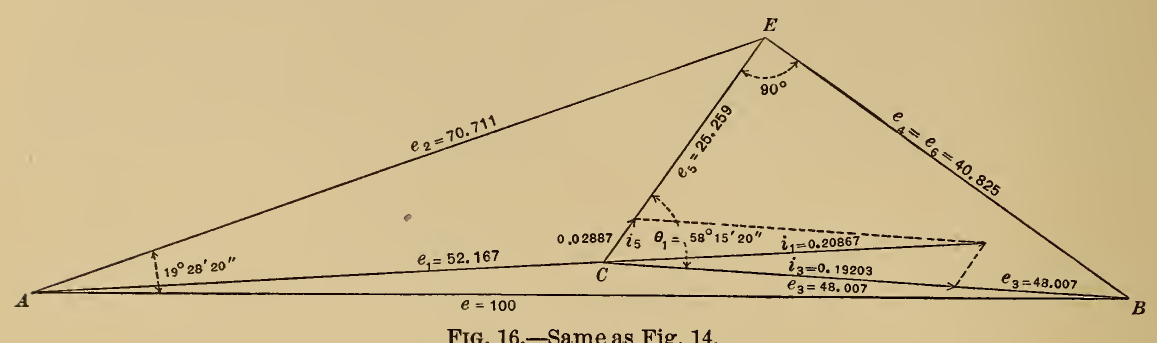

less. Nevertheless, their sum is greater, as the angle $\theta_{1}$ is reduced (as in the case of resistance in series) more than enough to offiset the reduction in the components. It is remarkable, in spite of all these

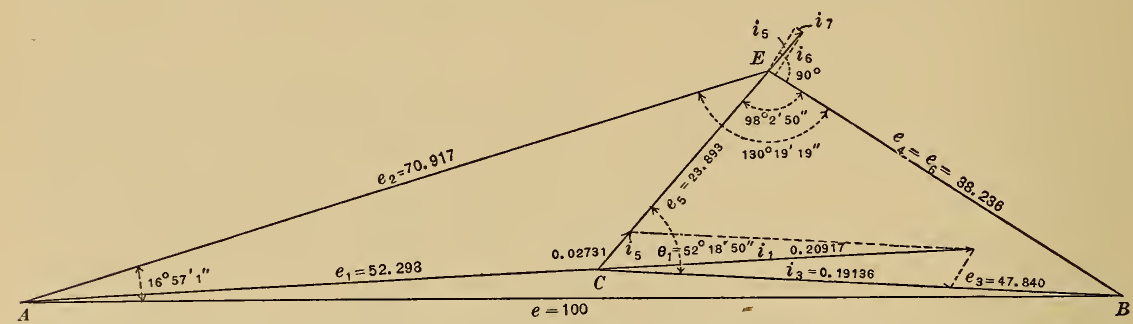

FIG. 17.-Showing effect of $10,000 \mathrm{ohms}$ in parallel with the condenser. Other conditions same as in Fig. 14.

changes and the large change in $Q$ (in this case from 500 to $600 \mathrm{ohms}$ ), that $r$ is entirely unchanged and the observed value of $L$ is also unchanged.

\section{MEASUREMENTS OF INDUCTANCE.}

We give in Tables VIII, IX, X, and XI the results obtained on several inductance coils of 100 millihenrys and smaller, measuring them singly and in series in groups of two or three. The two ratio coils $\mathrm{P}$ and $\mathrm{R}$ were each time reversed by a commutator and two settings of the variable resistance $r$ made. These two independent values of $r$ are given in columns 3 and 4, and their mean value in column 5. Referring to equation (13) above, if $P=R$, the inductance is

$$
L=C S(2 r+P)
$$




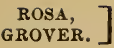

MEASUREMENT OF INDUCTANOE.

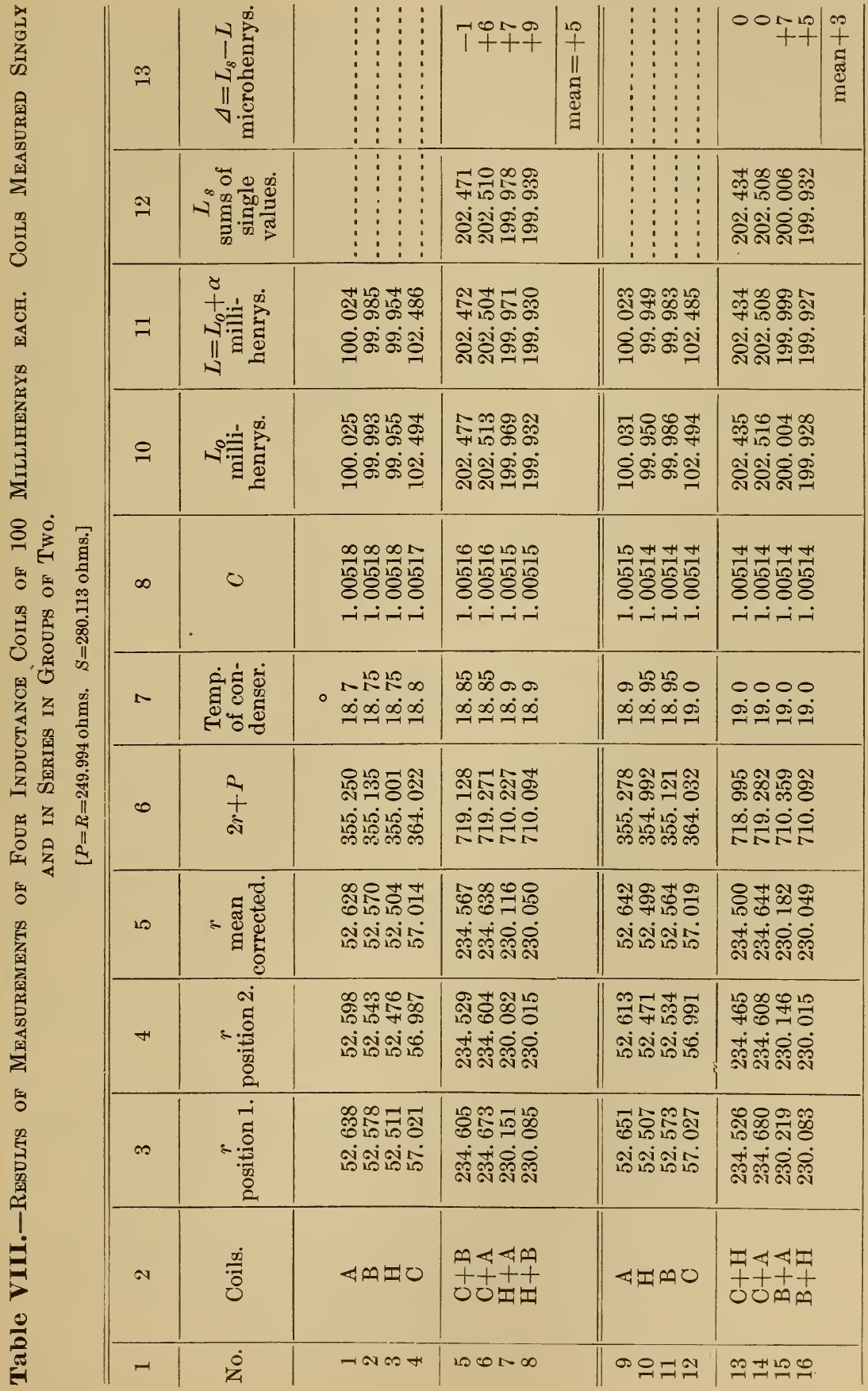


BULLETIN OF THE BUREAU OF STANDARDS. [VOL.1, No.3.

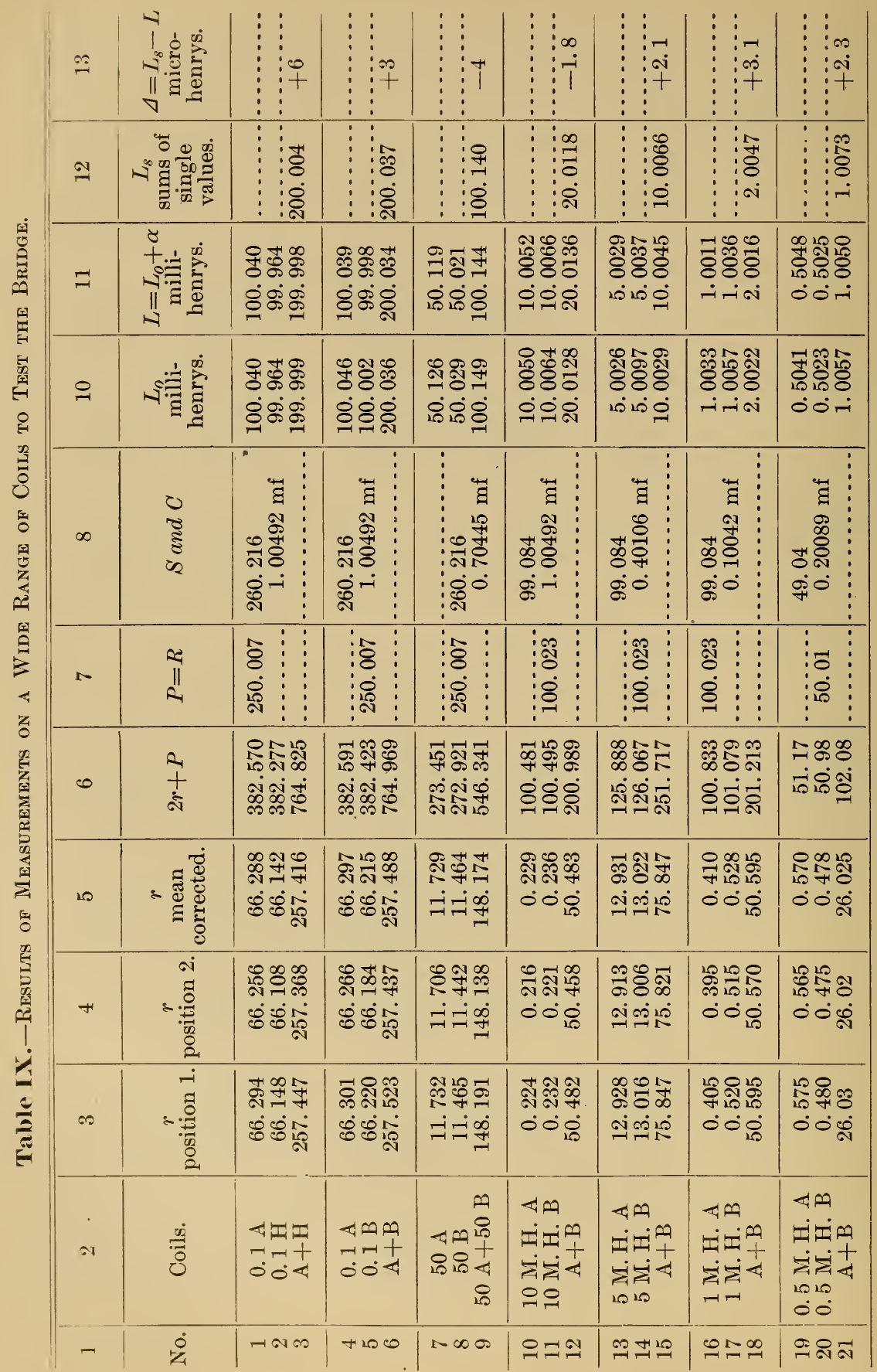


The values of $2 r+P$ are given in column 6 of the tables. The temperature of the condenser is given in column 7 of Table VIII, and its capacity at the given temperature in column 8. In Tables IX, X, and XI the temperature of the condenser was kept constant. The values of $L$, calculated from equation (24), are given in column 10 , and in column 11 are given the corrected values of $L$, obtained by applying the value of $\alpha$, which is sometimes positive and sometimes negative. In column 12 the sums $\left(L_{s}\right)$ of the separate values of $L$ are given, for comparison with the values opposite to them in column 11, obtained by measuring the coils in groups of two or three. The differences between the values of $L_{s}$ and $L$ are given in column 13 . These differences are discrepancies which indicate errors in the measured values of the inductances, but which amount on the average to only five parts in 200,000 for the 100-millihenry coils, and are sometimes positive and sometimes negative. They represent the errors of observation, the errors of the resistances, and the imperfections in the corrections for inductance and capacity of the arms of the bridge. The errors due to differences in $\mathrm{P}$ and $\mathrm{R}$ are eliminated by the commutator; the error due to inductance in $r$ we have seen to be inappreciable; the condenser is so good that no correction needs to be applied for its very slight absorption and leakage. In the second half of the table. the results are given for a remeasurement of the coils under conditions similar to those under which the first measurements were made. It will be noticed that the values agree very closely.

In Table IX the results are given of measurements on coils of 100 , $50,10,5,1.0$, and 0.5 millihenrys, using 4 of 100 millihenrys and 2 each of the other denominations, measuring them separately and in series in each. The residual differences between the corresponding values in columns 11 and 12 , and which amount to a very few microhenrys, are as small as could be expected.

In Table $\mathrm{X}$ the results are given of measurements on a coil $\mathrm{C}$ of nominally 100 millihenrys, and of two coils, A and B, of 50 millihenrys each, measured together as one coil and in series with the coil C. The residual differences between the sums of the separate values (column 12) and the measured sum (column 11) are given in column 13. They average about 4 in 200,000, being sometimes positive and sometimes negative. In Table XI similar results are given for the two 50millihenry coils measured separately and in series, with the residuals in column 13 averaging 6 parts in 100,000.

In both these tables the measurements are made with three different values of the resistances of the bridge $(P, R$, and $S$ being equal in every case) and three different currents for each separate value of the 
BULLETIN OF THE BUREAU OF STANDARDS. [VOL.1, No.3.

\begin{tabular}{|c|c|c|c|c|c|}
\hline$\dddot{7}$ & II & $\stackrel{\infty}{1}$ & $i$ & $i$ & $\stackrel{10}{+}$ \\
\hline 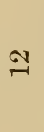 & 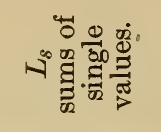 & 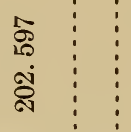 & $\begin{array}{l}\text { : } \\
\text { वें } \\
\text { वें }\end{array}$ & 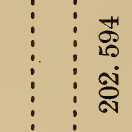 & 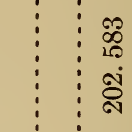 \\
\hline$=$ & 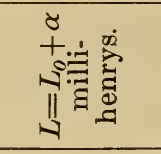 & 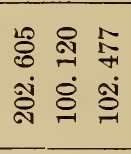 & 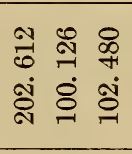 & 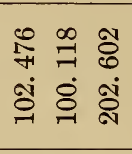 & 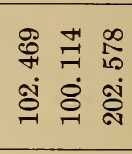 \\
\hline$\stackrel{ }{?}$ & 啌 & 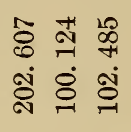 & 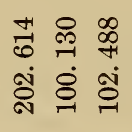 & 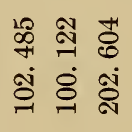 & 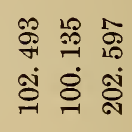 \\
\hline o & 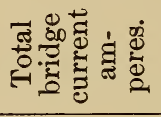 & \begin{tabular}{l}
$\stackrel{x}{\circ}$ \\
\hdashline
\end{tabular} & $\begin{array}{c}8 \\
\vdots \\
0 \\
\end{array}$ & $\begin{array}{c}0 \\
\vdots \\
0\end{array}$ & \begin{tabular}{l:} 
\\
\multirow{2}{*}{} \\
\hdashline \\
0
\end{tabular} \\
\hline$\infty$ & $\begin{array}{l}0 \\
\tilde{z} \\
\tilde{\sigma} \\
2 \\
2\end{array}$ & 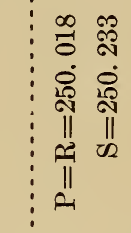 & $\begin{array}{l}\infty \\
\vdots \\
\vdots \\
\vdots \\
i \\
0 \\
0 \\
0\end{array}$ & & 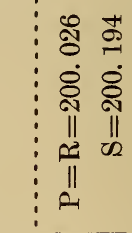 \\
\hline 0 & $\underset{c}{2}+$ & 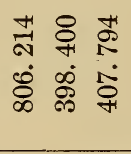 & 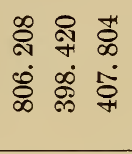 & 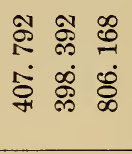 & 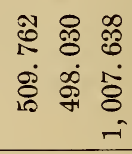 \\
\hline 10 & 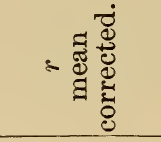 & 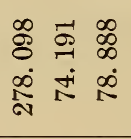 & 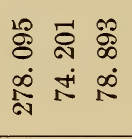 & 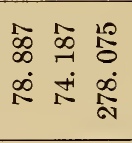 & 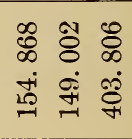 \\
\hline r & 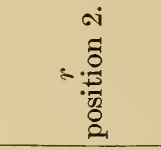 & 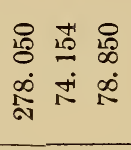 & 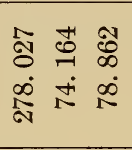 & 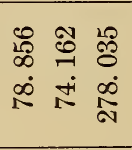 & 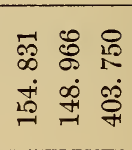 \\
\hline$\infty$ & 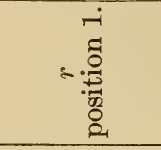 & 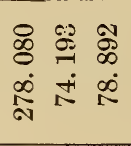 & 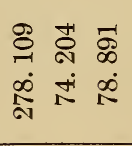 & 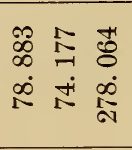 & 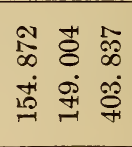 \\
\hline N & $\frac{\dot{0}}{\overline{\vec{\theta}}}$ & 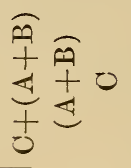 & 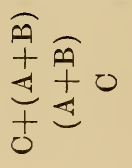 & 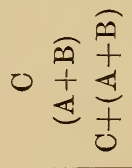 & 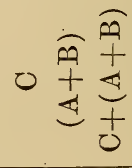 \\
\hline- & $\dot{8}$ & $\neg \infty$ & H 180 & $\wedge \infty$ & 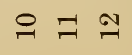 \\
\hline
\end{tabular}




\begin{tabular}{|c|c|c|c|c|}
\hline & $\begin{array}{l}\infty \\
\infty \\
a \\
a \\
\text { aิ } \\
\text { aे }\end{array}$ & $\begin{array}{l}\text { o } \\
\text { a } \\
\text { aें } \\
\text { aे }\end{array}$ & 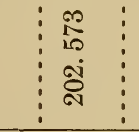 & 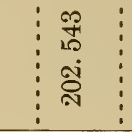 \\
\hline 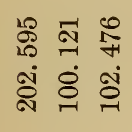 & 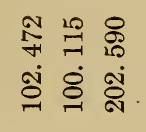 & 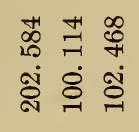 & 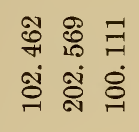 & 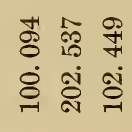 \\
\hline 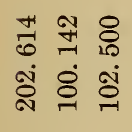 & 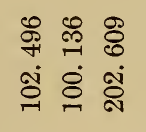 & 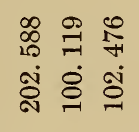 & 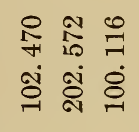 & 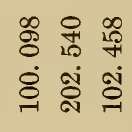 \\
\hline \begin{tabular}{l}
0 \\
\multirow{2}{*}{} \\
0 \\
0 \\
\end{tabular} & $\begin{array}{l}8 \\
0 \\
0\end{array}$ & 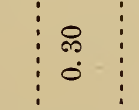 & ฌ̊ & $\stackrel{9}{\circ}$ \\
\hline : & & 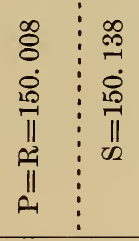 & & \\
\hline 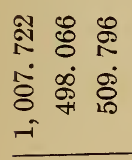 & 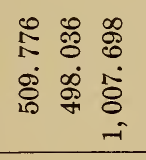 & 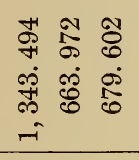 & 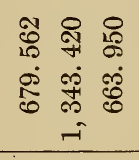 & 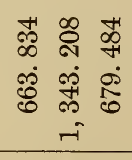 \\
\hline 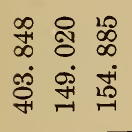 & 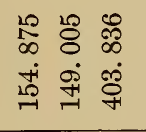 & 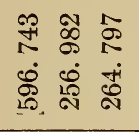 & 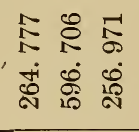 & 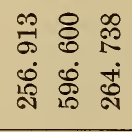 \\
\hline 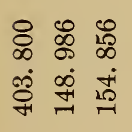 & 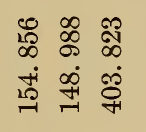 & 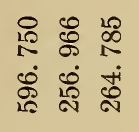 & 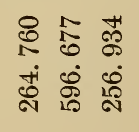 & 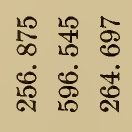 \\
\hline 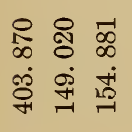 & 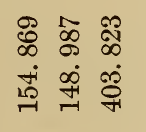 & 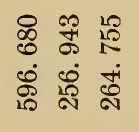 & 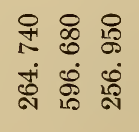 & 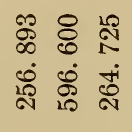 \\
\hline 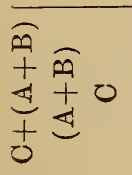 & 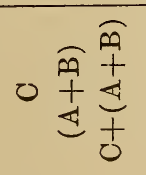 & 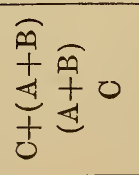 & 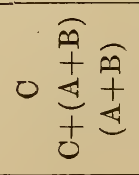 & 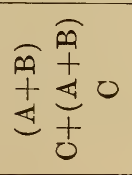 \\
\hline$\exists$ & $\stackrel{\oplus}{=} \stackrel{\infty}{=}$ & 오 오 స్ & ลิ สี & 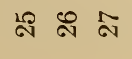 \\
\hline
\end{tabular}


BULLETIN OF THE BUREAU OF STANDARDS. [Vol.1, No.3.

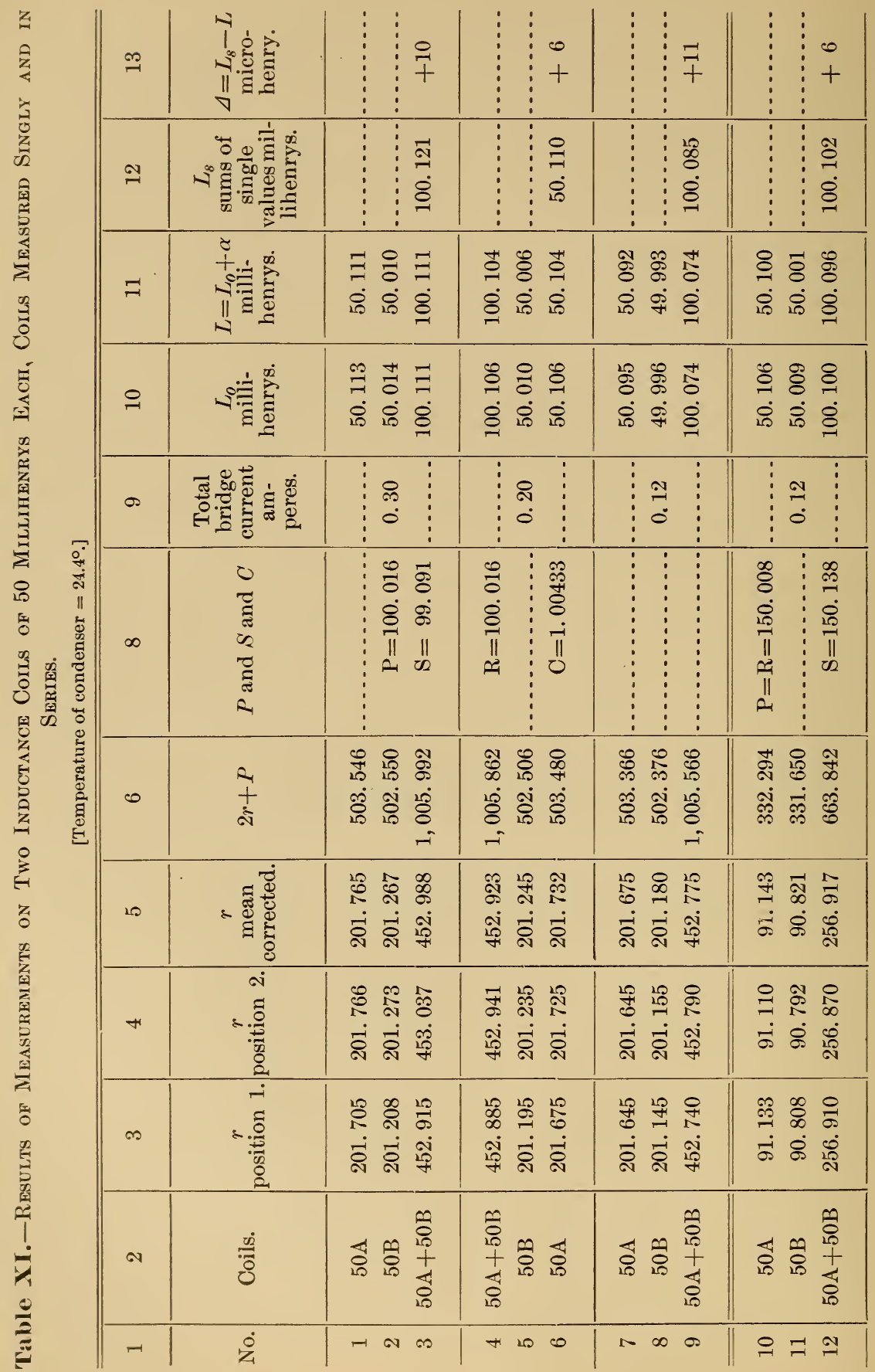




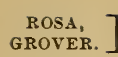

MEASUREMENT OF INDUCTANCE.

0

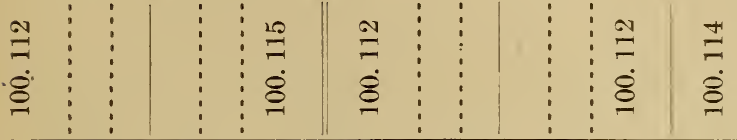

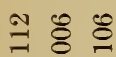

웡

옹 농

농

छ

요용

छิ

ํํㅇㅇ

羊官

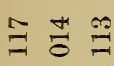

छे

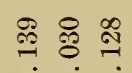

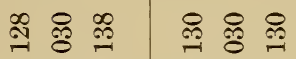

\& 80

옹

远

\begin{tabular}{|c|c|c|c|c|}
\hline \begin{tabular}{l} 
กิ \\
\hdashline
\end{tabular} & $\begin{array}{l}0 \\
0 \\
0 \\
0\end{array}$ & $\begin{array}{l}0 \\
0 \\
0\end{array}$ & $\begin{array}{c}\text { จ } \\
\vdots \\
0\end{array}$ & $\stackrel{9}{0}$ \\
\hline 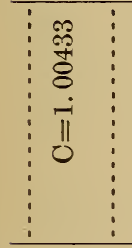 & & 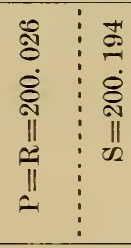 & 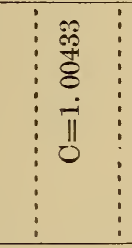 & \\
\hline 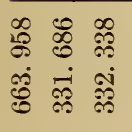 & 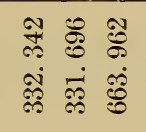 & 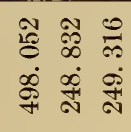 & 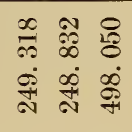 & 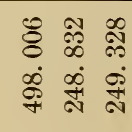 \\
\hline 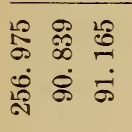 & 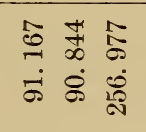 & 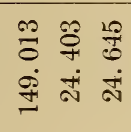 & 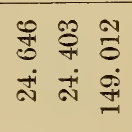 & 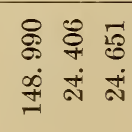 \\
\hline 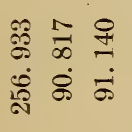 & 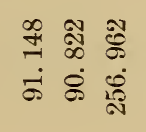 & 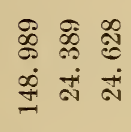 & 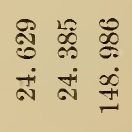 & 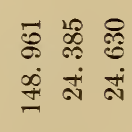 \\
\hline 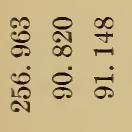 & 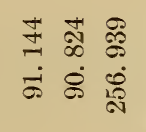 & 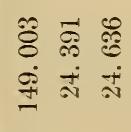 & 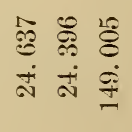 & 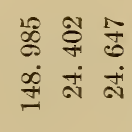 \\
\hline 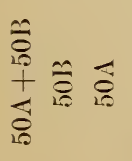 & 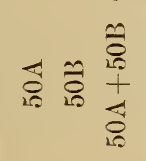 & 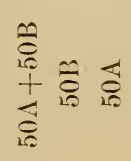 & 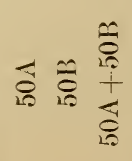 & 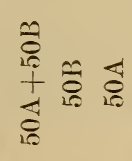 \\
\hline \pm 18 & $\mathscr{\imath}=\stackrel{x}{\sim}$ & $\Xi \bar{s}$ & ลิ ๙ิ ส & 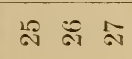 \\
\hline
\end{tabular}


Table XII.-Summary of Values of Inductances Shown in Table $\mathrm{X}$, with the Deviations from the Mean.

\begin{tabular}{|c|c|c|c|c|c|c|c|c|}
\hline 1 & 2 & 3 & 4 & 5 & 6 & 7 & 8 & 9 \\
\hline No. & $P=R=S$ & $\begin{array}{c}\text { Total } \\
\text { current } \\
\text { amperes }\end{array}$ & 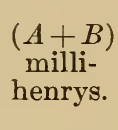 & $\begin{array}{c}\text { Devia- } \\
\text { tion } \\
\text { from } \\
\text { mean. }\end{array}$ & $\underset{\text { milli- }}{C}$ & $\begin{array}{c}\text { Devia- } \\
\text { tion } \\
\text { from } \\
\text { mean. }\end{array}$ & $\begin{array}{c}C+(A+B) \\
\text { milli- } \\
\text { henrys. }\end{array}$ & $\begin{array}{c}\text { Devia- } \\
\text { tion } \\
\text { from } \\
\text { mean. }\end{array}$ \\
\hline $\begin{array}{l}1 \\
2 \\
3\end{array}$ & $\begin{array}{c}250 \\
6 ،\end{array}$ & $\begin{array}{l}0.12 \\
0.20 \\
0.30\end{array}$ & $\begin{array}{l}100.120 \\
100.126 \\
100.118\end{array}$ & $\begin{array}{r}0.005 \\
.011 \\
.003\end{array}$ & $\begin{array}{l}102.477 \\
102.480 \\
102.476\end{array}$ & $\begin{array}{r}0.007 \\
.010 \\
.006\end{array}$ & $\begin{array}{l}202.605 \\
202.612 \\
202.602\end{array}$ & $\begin{array}{r}0.019 \\
.026 \\
.016\end{array}$ \\
\hline $\begin{array}{l}4 \\
5 \\
6\end{array}$ & $\begin{array}{c}200 \\
6 \\
\text { " }\end{array}$ & $\begin{array}{l}0.12 \\
0.20 \\
0.30\end{array}$ & $\begin{array}{l}100.114 \\
100.121 \\
100.115\end{array}$ & $\begin{array}{c}.001 \\
.006 \\
0\end{array}$ & $\begin{array}{l}102.469 \\
102.476 \\
102.472\end{array}$ & $\begin{array}{l}.001 \\
.006 \\
.002\end{array}$ & $\begin{array}{l}202.578 \\
202.595 \\
202.590\end{array}$ & $\begin{array}{l}.008 \\
.009 \\
.014\end{array}$ \\
\hline $\begin{array}{l}7 \\
8 \\
9\end{array}$ & $\begin{array}{l}150 \\
، " ،\end{array}$ & $\begin{array}{l}0.12 \\
0.20 \\
0.30\end{array}$ & $\begin{array}{l}100.094 \\
100.111 \\
100.114\end{array}$ & $\begin{array}{l}.021 \\
.004 \\
.001\end{array}$ & $\begin{array}{l}102.449 \\
102.462 \\
102.468\end{array}$ & $\begin{array}{l}.021 \\
.008 \\
.002\end{array}$ & $\begin{array}{l}202.537 \\
202.569 \\
202.584\end{array}$ & $\begin{array}{l}.049 \\
.017 \\
.002\end{array}$ \\
\hline & & Means. & 100.115 & .006 & 102.470 & .007 & 202.586 & .018 \\
\hline
\end{tabular}

Table XIII.-Summary of Values of Inductances Shown in Table XI, with the Deviations from the Mean.

\begin{tabular}{|c|c|c|c|c|c|c|c|c|}
\hline 1 & 2 & 3 & 4 & 5 & 6 & 7 & 8 & 9 \\
\hline No. & $P=R=S$ & $\begin{array}{c}\text { Total } \\
\text { current } \\
\text { am- } \\
\text { peres. }\end{array}$ & $\underset{\text { milli- }}{A} \underset{\text { henrys. }}{A}$ & $\begin{array}{c}\text { Devia- } \\
\text { tion } \\
\text { from } \\
\text { mean. }\end{array}$ & $\underset{\text { milli- }}{B}$ & $\begin{array}{c}\text { Devia- } \\
\text { tion } \\
\text { from } \\
\text { mean. }\end{array}$ & $A+B$ & $\begin{array}{l}\text { Devia- } \\
\text { tion } \\
\text { from } \\
\text { mean. }\end{array}$ \\
\hline $\begin{array}{l}1 \\
2 \\
3\end{array}$ & $\begin{array}{c}100 \\
6 " 6\end{array}$ & $\begin{array}{l}0.12 \\
0.20 \\
0.30\end{array}$ & $\begin{array}{l}50.092 \\
50.104 \\
50.111\end{array}$ & $\begin{array}{r}0.012 \\
.000 \\
.007\end{array}$ & $\begin{array}{l}49.993 \\
50.006 \\
50.010\end{array}$ & $\begin{array}{r}0.012 \\
.001 \\
.005\end{array}$ & $\begin{array}{l}100.074 \\
100.104 \\
100.111\end{array}$ & $\begin{array}{r}0.033 \\
.003 \\
.004\end{array}$ \\
\hline $\begin{array}{l}4 \\
5 \\
6\end{array}$ & $\begin{array}{c}150 \\
6 \\
6\end{array}$ & $\begin{array}{l}0.12 \\
0.20 \\
0.30\end{array}$ & $\begin{array}{l}50.100 \\
50.106 \\
50.107\end{array}$ & $\begin{array}{l}.004 \\
.002 \\
.003\end{array}$ & $\begin{array}{l}50.001 \\
50.006 \\
50.008\end{array}$ & $\begin{array}{l}.004 \\
.001 \\
.003\end{array}$ & $\begin{array}{l}100.096 \\
100.112 \\
100.113\end{array}$ & $\begin{array}{l}.011 \\
.005 \\
.006\end{array}$ \\
\hline \multirow[t]{2}{*}{$\begin{array}{l}7 \\
8 \\
9\end{array}$} & $\begin{array}{c}200 \\
6 \\
6\end{array}$ & $\begin{array}{l}0.12 \\
0.20 \\
0.30\end{array}$ & $\begin{array}{l}50.107 \\
50.105 \\
50.105\end{array}$ & $\begin{array}{l}.003 \\
.001 \\
.001\end{array}$ & $\begin{array}{l}50.007 \\
50.007 \\
50.007\end{array}$ & $\begin{array}{l}.002 \\
.002 \\
.002\end{array}$ & $\begin{array}{l}100.111 \\
100.119 \\
100.120\end{array}$ & $\begin{array}{l}.004 \\
.012 \\
.013\end{array}$ \\
\hline & & Means. & 50.104 & .004 & 50.005 & .004 & 100.107 & .010 \\
\hline
\end{tabular}


resistances. This gives nine measurements of each coil and of the sum of the coils. These nine values of each coil and of their sums are given in Tables XII and XIII, with their deviations from the mean. In most cases the values are a little smaller with the smaller currents and smaller resistances. We have not yet ascertained why this is so; perhaps the resistances were not as accurately known as we supposed.

In Table XIV the measurements of April 21 are given, three coils of 1 henry each being taken singly and in series in groups of two and three.

The separate values found during the day for the three coils are given in Table XV. The small increase in the value of $L$ may be due in part to uncertainty in the change of capacity of the condenser. The latter changed in temperature, according to the thermometer, by $0^{\circ} .75$, and that corresponds to 11 parts in 100,000 in the capacity. The slight progressive changes in the values of the inductances of the coils may be accounted for by a quarter of a degree greater change in the temperature of the condenser than indicated by the thermometer, or a slightly greater temperature coefficient. We shall investigate this further, keeping the temperature of the condenser constant, to decide whether the coils really change in the manner indicated.

Table XV.-Results of the Determinations of the Inductance of Three Coils of 1 Henry each, April 21, 1905.

\begin{tabular}{c|c|c}
\hline Coil F. & Coil S. & Coil C. \\
\hline Henrys. & Henrys. & Henrys. \\
0.99890 & 0.99969 & 1.01420 \\
.99892 & .999715 & 1.01421 \\
.99894 & .99970 & 1.01422 \\
.99895 & .999715 & 1.01422 \\
.99895 & .99972 & \\
\hline
\end{tabular}

The regularity of this progressive change shows that some common cause affects all the measurements, but the changes are very small indeed, amounting to only a few parts in a hundred thousand. The sensitiveness of the bridge is well shown by these results, and if we can eliminate the small residual errors of the bridge completely, it will make it possible to measure inductances with far greater accuracy than has been done heretofore.

In order to make these measurements under the most favorable circumstances, we have designed and are now constructing a bridge espe- 
BULLETIN OF THE BUREAU OF STANDARDS. [Vol.1, No.3.

\begin{tabular}{|c|c|c|c|c|c|c|}
\hline 量 & $\cong$ & $i_{0}^{n}$ & 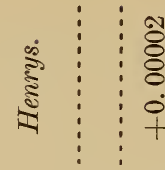 & 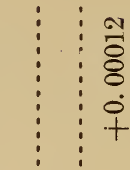 & $\begin{array}{ll} & 8 \\
\vdots & 8 \\
\vdots & 8 \\
\vdots & 0 \\
\vdots & +\end{array}$ & $\begin{array}{l}\text { थै } \\
\text { ᄋे } \\
8 \\
8 \\
0 \\
0 \\
+ \\
+\end{array}$ \\
\hline 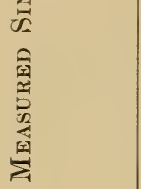 & $\stackrel{-1}{-1}$ & 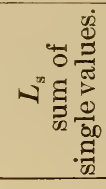 & 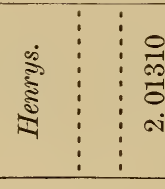 & $\begin{array}{ll} & -1 \\
\vdots & 8 \\
\vdots & 8 \\
\vdots & -1\end{array}$ & \begin{tabular}{cc} 
& \multicolumn{2}{c}{} \\
$\vdots$ & \\
$\vdots$ & 0 \\
$\vdots$ & 0 \\
$\vdots$ & ai
\end{tabular} & 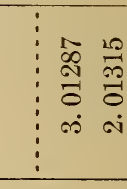 \\
\hline 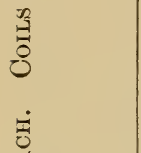 & $=$ & 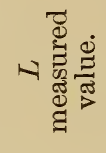 & 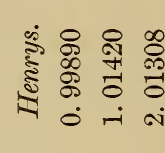 & 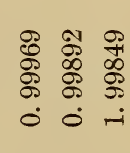 & 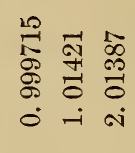 & 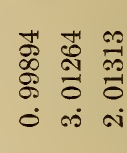 \\
\hline 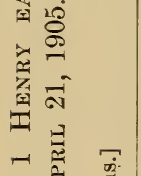 & $\infty$ & 0 & 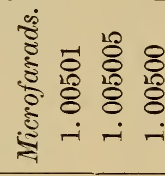 & 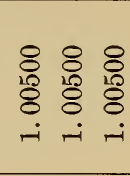 & 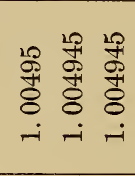 & 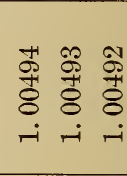 \\
\hline 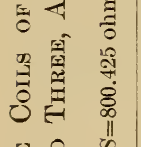 & $\infty$ & 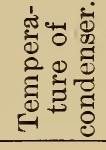 & 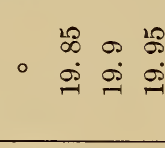 & 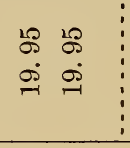 & 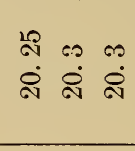 & 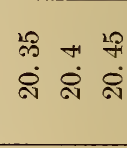 \\
\hline 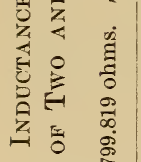 & 0 & $\begin{array}{l}a \\
+ \\
i \\
\text { iv }\end{array}$ & 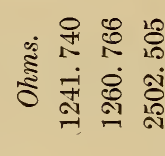 & 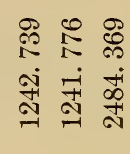 & 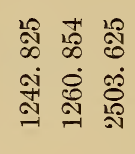 & 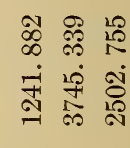 \\
\hline 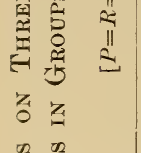 & 10 & 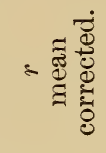 & 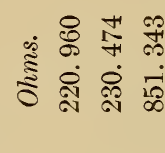 & 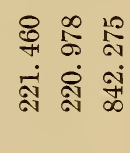 & 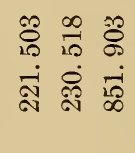 & 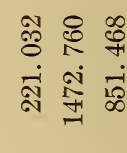 \\
\hline 葸 & t & 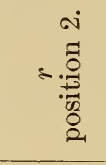 & 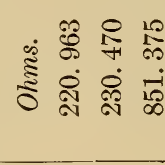 & 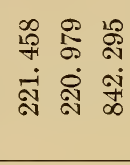 & 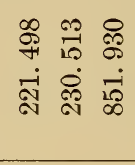 & 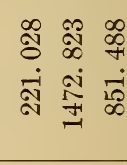 \\
\hline & $\infty$ & =. & 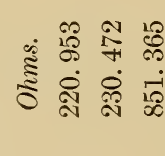 & 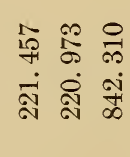 & 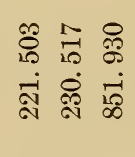 & 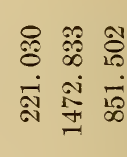 \\
\hline & N & $\frac{\dot{\theta}}{\ddot{0}}$ & I I 0 亲 & 吸区 & $\pi 0 \underset{\infty}{+}$ & {$\left[\begin{array}{l}0 \\
+ \\
0 \\
+ \\
x_{1}\end{array}\right.$} \\
\hline & - & $\dot{0}$ & $r \infty \infty$ & +200 & $1 \infty a$ & $\stackrel{ }{=} \stackrel{-}{-}$ \\
\hline
\end{tabular}




\begin{tabular}{|c|c|c|}
\hline $\begin{array}{l}\infty \\
8 \\
8 \\
\vdots \\
\vdots\end{array}$ & $\begin{array}{l:}5 \\
8 \\
8 \\
0 \\
+\end{array}$ & 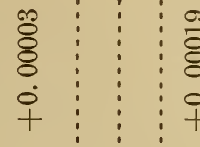 \\
\hline $\begin{array}{l}18 \\
80 \\
8 \\
8 \\
8 \\
-1\end{array}$ & 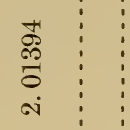 & $\begin{array}{l}\sqrt[1]{6} \\
\overrightarrow{0} \\
\text { a }\end{array}$ \\
\hline 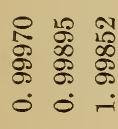 & 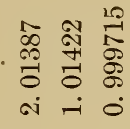 & 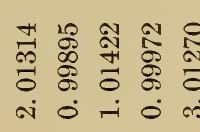 \\
\hline 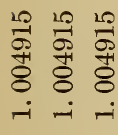 & 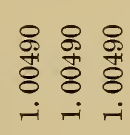 & 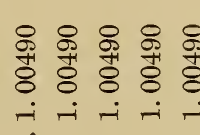 \\
\hline مी & 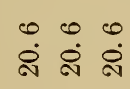 & 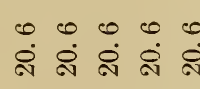 \\
\hline 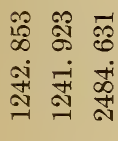 & 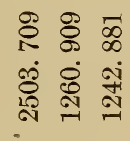 & 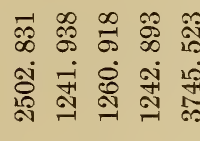 \\
\hline 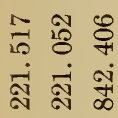 & 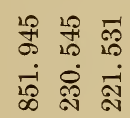 & 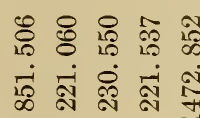 \\
\hline 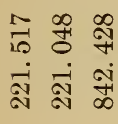 & 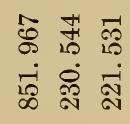 & 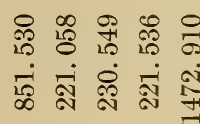 \\
\hline 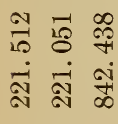 & 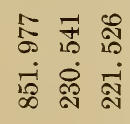 & 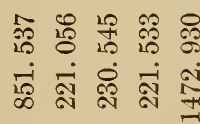 \\
\hline 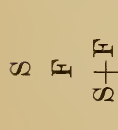 & $\begin{array}{l}\pi \\
+\end{array} 0$ & $\underset{t}{0} \underbrace{}_{1}$ \\
\hline$\underset{72}{20}$ & $\stackrel{0}{\sim} \approx \stackrel{\infty}{=}$ & 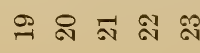 \\
\hline
\end{tabular}


cially adapted to this work. The bridge we have been using has been made up of several different resistance boxes. The resistances were all immersed in oil, the temperatures were accurately taken, they were frequently measured against our standards, and every effort made to get precise results. But with all combined in a single set, with shorter and more permanent connections between the arms of the bridge and the residual inductances and capacities eliminated more completely, we hope to improve upon the results given above, and make sure of the value of the inductance of a standard coil to at least one part in ten thousand, barring the uncertainty in the ohm itself. When this has been accomplished we hope to determine some inductance coils, the dimensions of which shall have been accurately determined, and the inductances computed therefrom, in order to obtain a check upon the value of the ohm.

The Anderson bridge, used in the manner we have described above, is admirably adapted to practical use in measuring inductances of a great range of values. Its accuracy far exceeds most of the methods that have been proposed, and it is more convenient than any method we have employed that can compare with it in accuracy.

Note.-Since the above was written we have discovered that the serpentine spools on which the inductances $F$ and $S$ of 1 henry each and several of 0.1 henry are wound are slightly magnetic, and that their permeability is larger with higher magnetizing force. Consequently the inductances of the coils are not quite constant, but vary when the voltage on the bridge or the resistances of the arms of the bridge are varied. This would cause the sum of two inductances measured separately to be a little greater than when measured together, and this accounts for the discrepancies $\Delta$ in column 13 of Table XIV, all being of the same sign, and larger when coils $F$ and $S$ (both being wound on serpentine spools) are taken together than when $F$ and $C$ or $S$ and $C$ are taken together, $C$ being wound on a mahogany spool and therefore not magnetic.

In the case of coils of 0.1 henry or less the current is reduced very little when two are put in series in the bridge, and hence the resultant change in the inductance is much less.

We give in another article in this bulletin the results of tests made to determine the magnitude of the effect of this small amount of magnetic matter in the spools. 

